Boletín de la Sociedad Geológica Mexicana

Volumen Conmemorativo del Centenario

Grandes Fronteras Tectónicas de MéXico

Tomo LVII, NÚM. 1, 2005, P. 27-52

\title{
La falla San Marcos: una estructura jurásica de basamento multirreactivada del noreste de México
}

\author{
Gabriel Chávez-Cabello ${ }^{1,2, *}$, José J. Aranda-Gómez ${ }^{3,4}$, Roberto S. Molina-Garza ${ }^{4}$, Tomás \\ Cossío-Torres ${ }^{2,5}$, Irving R. Arvizu-Gutiérrez ${ }^{1}$ y \\ Gildardo A. González-Naranjo ${ }^{5}$ \\ ${ }^{1}$ Posgrado en Ciencias de la Tierra, Centro de Geociencias, Universidad Nacional Autónoma de México, \\ Campus Juriquilla, Apartado postal 1-742, Querétaro, Qro., 76001, México \\ ${ }^{2}$ Facultad de Ciencias de la Tierra, Universidad Autónoma de Nuevo León, \\ Apartado postal 104, Kilómetro 8, Carretera Linares-Cerro Prieto, Linares, N. L., 67700, México \\ ${ }^{3}$ Departamento de Geología Económica, Instituto Potosino de Investigación Científica y Tecnológica, \\ Apartado postal 3-74, San Luis Potosí, S.L.P., 78216, México \\ ${ }^{4}$ Centro de Geociencias, Universidad Nacional Autónoma de México, Campus Juriquilla, \\ Apartado postal 1-742, Querétaro, Qro., 76001, México \\ ${ }_{5}^{5}$ Posgrado en Ciencias de la Tierra, Facultad de Ciencias de la Tierra, Universidad Autónoma de Nuevo León, \\ Apartado postal 104, Kilómetro 8, Carretera Linares-Cerro Prieto, Linares, N. L., 67700, México \\ * gabchave@hotmail.com
}

\section{Resumen}

La falla San Marcos (FSM) es un lineamiento estructural regional con más de $300 \mathrm{~km}$ de largo, rumbo WNW y que se inclina hacia el NNE, separando el bloque de Coahuila del Cinturón Plegado de Coahuila en el noreste de México. La FSM es una estructura de basamento multirreactivada que, en superficie, muestra evidencias estratigráficas y estructurales que documentan su actividad intermitente por lo menos desde el Jurásico Tardío hasta el Plioceno-cuaternario. Las evidencias estructurales más antiguas reconocidas en este trabajo documentan actividad de la FSM durante tiempos pre-Titoniano y Neocomiano, sugiriendo que la FSM acomodó principalmente extensión de la corteza en dirección NNE. Esta extensión contribuyó al crecimiento de la cuenca de Sabinas; con lo anterior, se pone en duda la existencia de grandes desplazamientos laterales a través de la FSM por lo menos para estos tiempos.

Se han reconocido al menos cuatro eventos de reactivación de la FSM. El primero fue con componente normal en el Neocomiano y causó el depósito de la Formación San Marcos. El segundo evento de reactivación fue inverso en el Paleógeno y debió incluir a fallas menores asociadas a la FSM. Se interpreta que el segundo evento de reactivación está representado por la ocurrencia de: a) plegamiento tipo drape y transporte tectónico menor hacia el sur-suroeste sobre la traza principal de la FSM, b) ocurrencia de relaciones perpendiculares entre los ejes de pliegues en la parte suroeste de la cuenca de Sabinas, c) por el levantamiento de rocas más antiguas progresivamente hacia el noreste dentro del Valle San Marcos (VSM) y d) por la existencia de direcciones perpendiculares de transporte tectónico determinadas para diferentes estructuras en el VSM (e.g. fallas en el sector oeste del VSM registran transporte hacia el oeste y fallas en el sector suroeste registran transporte hacia el sur-suroeste). Las fallas menores asociadas a la FSM presentan orientaciones desde E-W hasta cercanamente N-S como las fallas El Caballo y El Almagre expuestas al oeste de Coahuila y sureste de Chihuahua. Este evento de reactivación inverso de la FSM es tardío con respecto a una fase anterior de despegues (duplicación de la secuencia por fallas) en localidades de la plataforma de Coahuila y la cuenca de Sabinas. La importancia y escala de los despegues debe ser explorado con mayor detalle en futuros trabajos.

La tercera reactivación es normal con componente lateral izquierda (Mioceno tardío-Plioceno temprano) y, la cuarta y última, predominantemente normal (Plioceno - cuaternario). Estas reactivaciones fueron reconocidas sobre la traza de la 
FSM sepultada por productos del Campo Volcánico de Camargo, al sureste de Chihuahua. Los dos últimos eventos parecen estar presentes sobre los segmentos de la FSM en Coahuila; sin embargo, aquí no afectan a rocas jóvenes por lo que no es posible establecer sus edades.

Palabras clave: Falla San Marcos, cuenca de Sabinas, Cinturón Plegado de Coahuila, Coahuila, Noreste de México.

Abstract

San Marcos Fault (FSM) is a regional lineament in northeast Mexico with a minimum length of $300 \mathrm{~km}$ separating the Coahuila block from the Coahuila Fold Belt; the fault dip NNE and strike WNW. FSM is a basement fault that has been reactivated multiple times, and along its trace there is an stratigraphic and structural evidence of intermittent activity since at least the Late Jurassic to the Pliocene-Quaternary. The oldest structural evidence recognized in this work suggests the FSM accommodated mainly NNE crustal extension in pre-Tithonian and Neocomian time. This extension may have contributed to development and growth of the Sabinas basin to the north; this in turn casts doubts on previously proposed existence of large lateral slip across the fault in Late Jurassic time.

At least four reactivation events have been recognized along the FSM. The first, in the Neocomian, was normal and triggered deposition of the San Marcos Formation. The second reactivation of the FSM involved reverse slip during Paleogene time, and it causes minor folds associated to the FSM. Interpretation of the reactivation event of FSM as a reverse fault is based on: (a) the occurrence of drape folds and minor tectonic transport to the south-southwest along the main trace of the fault; (b) the occurrence of a nearly perpendicular relation between fold axes of different generation in the southwest sector of the Sabinas basin; (c) uplift of progressively older rocks towards the northeast within San Marcos valley (VSM); and, (d) by the existence of near perpendicular directions of tectonic transport determined for different structures within VSM (e.g., faults in the western sector of the valley record tectonic transport to the west and faults in the southwest sector of the valley record tectonic transport to the south-southwest). Minor faults associated with the FSM vary in orientation from nearly E-W to nearly N-S, and are best represented by the El Caballo and El Almagre faults, exposed western Coahuila and southeastern Chihuahua. Reactivation as a reverse fault occurred late, relative to a earlier stage of detachment (locally duplicating the stratigraphic sequence) in localities over the Coahuila platform and Sabinas basin itself. The relative importance and scale of detachment folds needs to be explored with further detail.

The third reactivation event is normal to a left-lateral component (late Miocene-early Pliocene), and the fourth and last event is dominantly normal (Pliocene-Quaternary). The last two reactivations events along the FSM were recognized along the segment of the fault buried by volcanic products of the Camargo Volcanic Field, in southeast Chihuahua state. These late events appear to be present along the FSM in Coahuila, but here they do not affect Cenozoic sequence that would allow to establish the age of faulting.

Key words: San Marcos Fault, Sabinas basin, Coahuila Fold Belt, Coahuila, Northeastern Mexico.

\section{Introducción}

La falla San Marcos (FSM) fue definida por Charleston (1981) y es la única falla de basamento en el noreste de México para la que se han compilado en superficie evidencias estratigráficas y estructurales que documentan su existencia de forma convincente (Charleston, 1981; Padilla y Sánchez, 1982, 1986; McKee et al., 1984, 1990). La traza de la FSM tiene una longitud mínima de $300 \mathrm{~km}$, cruza con un rumbo WNW al estado de Coahuila dividiéndolo en dos partes y se inclina hacia el NNE; la falla separa estructuralmente el bloque de Coahuila del Cinturón Plegado de Coahuila (CPC; Figura 1). Se ha sugerido que la FSM puede extenderse otros $300 \mathrm{~km}$ más hacia el WNW de la localidad de Sierra Mojada (Aranda-Gómez et al., en prensa, a), sólo que ese segmento se encuentra sepultado por una cubierta gruesa de rocas volcánicas del Paleógeno y Neógeno. La FSM también ha sido nombrada Lineamiento Sierra Mojada-China (Padilla y Sánchez, 1982).

A diferencia de otras fallas del basamento en el norte de México, como la falla Mojave-Sonora (Anderson y Schmidt, 1983) y la falla La Babia (Charleston, 1981), esta última también conocida como Lineamiento Boquillas del Carmen-Sabinas (Padilla y Sánchez, 1982) o falla Sabinas (Alfonso, 1978), la traza de la FSM parece ser muy clara entre el Potrero La Gavia, valle San Marcos (VSM), Potrero Colorado y Sierra Mojada por: a) separar estilos de deformación diferentes entre el bloque de Coahuila y el $\mathrm{CPC}, \mathrm{b})$ por la cuña de sedimentos clásticos ( 750 a 3000 $\mathrm{m}$ de espesor) pre-titoniana y neocomiana asociada a su 


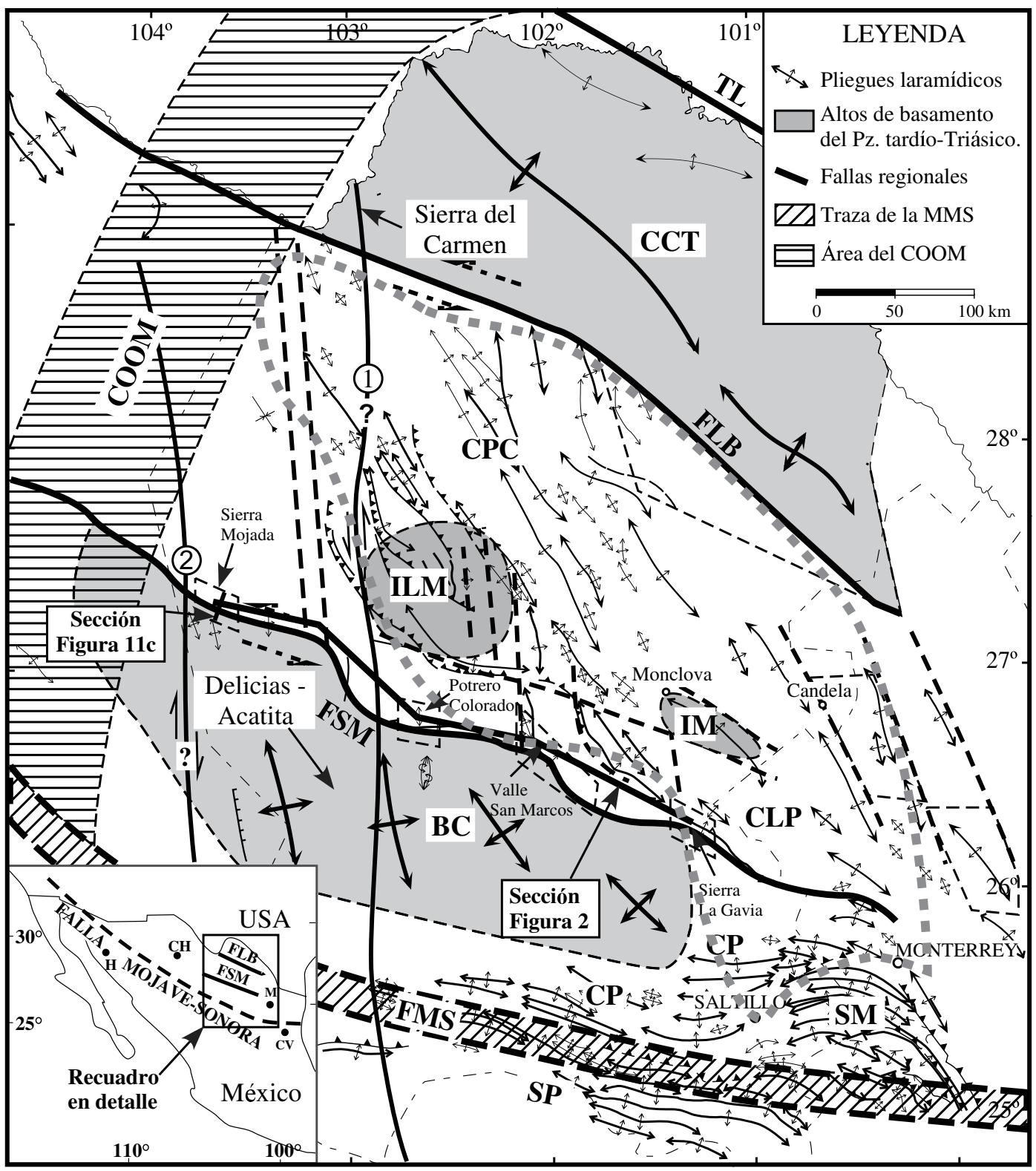

Figura 1. Mapa geológico generalizado del estado de Coahuila y regiones adyacentes. En él se muestran la localización de las estructuras mayores de basamento como el Texas Lineament (TL), las fallas de La Babia (FLB), San Marcos (FSM) y la traza inferida de la falla Mojave-Sonora (FMS). Nótese que las fallas La Babia y San Marcos separan regiones con estilos contrastantes de deformación, como el cratón Coahuila-Texas (CCT) del Cinturón Plegado de Coahuila (CPC), y éste a su vez del bloque de Coahuila (BC), respectivamente. Estructuras de segundo orden en el basamento también parecen limitar a rasgos paleogeográficos importantes como la isla La Mula (ILM) e isla de Monclova (IM). Otros rasgos morfológico-estructurales como la Saliente de Monterrey (SM), Sierra de Parras (SP) y las cuencas de antepaís de Parras (CP) y La Popa (CLP), falla Almagre (1) y El Caballo (2) también son señaladas, así como varias localidades citadas en el texto. La franja marcada COOM representa a la prolongación sepultada del Cinturón Orogénico OuachitaMarathon. La línea gris punteada gruesa entre el BC y el CCT representa a los límites de la cuenca de Sabinas de acuerdo con Eguiluz (2001).

actividad y depositada en el bloque hundido al NNE de la falla (Figura 2; McKee et al., 1990) y, c) por la ocurrencia de relaciones de contacto de rocas pérmicas con jurásicas y con rocas cretácicas en el VSM y Potrero Colorado, lo cual ocurre a través de fallas que se inclinan al NNE con ángulo alto. Además, en los lugares donde la traza de la FSM se encuentra sepultada (e.g., campo volcánico de Camargo), se sugiere que ésta generó rasgos en superficie que definen levantamientos y/o desplazamientos laterales, así como que también pudo haber canalizado magmatismo basáltico del Plio-cuaternario que sugiere su existencia a la profundidad (Aranda-Gómez et al., 2003; Aranda-Gómez et al., en prensa, b).

A pesar de la importancia de la FSM y de estructuras paralelas a ella como la falla Mojave-Sonora y la falla La Babia en la interpretación de la evolución tectónica del noreste de México, las investigaciones estructurales sobre ésta, hasta antes de este trabajo, habían estado limitadas a 
la interpretación de fotografías aéreas y de imágenes de satélite, con lo que se definieron los estilos de deformación que la FSM separa entre el bloque de Coahuila y el CPC (Charleston, 1981; Padilla y Sánchez, 1982). Es importante hacer énfasis en que la mayoría de los rasgos visibles en fotos aéreas e imágenes de satélite son rasgos asociados a la deformación Laramide del Paleógeno y no a la deformación del Jurásico Tardío.

El objetivo del presente trabajo es discutir las evidencias estructurales que documentan la cinemática de la FSM desde su instauración pre-titoniana hasta su último evento de reactivación en el Neógeno - cuaternario para la parte central de Coahuila. Esto se hace en parte mediante un estudio comparativo de las familias de fallas entre las localidades de VSM, Potrero Colorado y Sierra Mojada, donde desde el punto de vista estratigráfico McKee et al. (1990) definieron con mayor detalle la existencia de la FSM y sus primeros dos eventos de reactivación (Neocomiano y Paleógeno). Por otro lado, las interpretaciones de este trabajo sobre las reactivaciones del Neógeno-cuaternario de la FSM en Coahuila, se comparan con los eventos de reactivación para este mismo tiempo documentados por Aranda-Gómez et al. (en prensa, a) en las localidades de Aguachile, La Herradura y campo volcánico de Camargo. Lo anterior, permitió realizar un análisis regional del evento de formación de la FSM en tiempos pre-Titoniano y de sus diferentes reactivaciones hasta el Neógeno - cuaternario. De acuerdo con lo establecido en este trabajo y lo reportado en la literatura, la actividad de la FSM inició antes del Titoniano y ha experimentado al menos cuatro eventos de reactivación, los cuales se abordan sistemáticamente más adelante.

\section{Secuencias estratigráficas asociadas a la actividad de la falla San Marcos}

La evidencia observable más contundente de la actividad más antigua de la FSM es estratigráfica, y se interpreta por la existencia de una cuña de sedimento clástico marino titoniana y anterior a este tiempo, depositada en el bloque ubicado al norte de la falla (i.e. cuenca La Mula o Sabinas). La cuña clástica tiene $2000 \mathrm{~m}$ de espesor, fue dividida en tres unidades litoestratigráficas informales definidas por McKee et al. (1990) como: capas Las Palomas, capas Sierra El Granizo y capas Tanque Cuatro Palmas (Figura 2); la última unidad es correlacionable con la Formación La Casita del Kimmeridgiano-Berriasiano inferior en el noreste de México (McKee et al., 1990) y representa una etapa de quietud tectónica después de la actividad intensa que controló el depósito de las capas Las Palomas y Sierra El Granizo. A los primeros $1600 \mathrm{~m}$ de rocas clásticas sintectónicas asociadas a actividad pre-titoniana de la FSM (capas Las Palomas y Sierra El Granizo), se suman los 400 $\mathrm{m}$ de las capas Tanque Cuatro Palmas (etapa de quietud tectónica) y $1000 \mathrm{~m}$ más que corresponden al primer evento de reactivación del Neocomiano y que están compuestos por conglomerado continental y arenisca fluvial de la Formación San Marcos (Figura 2). Existen argumentos convincentes de que la fuente de estos detritos es el bloque de Coahuila, al sur de la FSM, el cual en conjunto está compuesto por sedimentos marinos masivos y rocas volcánicas de la cuenca y el arco Las Delicias (Pensilvánico-Pérmico) y por cuerpos intrusivos del Pérmico-Triásico (McKee et al., 1984; 1990; McKee et al., 1988; 1999).

Es importante señalar que, debido a la ausencia de fósiles diagnóstico que puedan precisar la edad de las capas Las Palomas y Sierra El Granizo, no se puede descartar la posibilidad de que estas capas sean correlacionables con los materiales clásticos del Grupo Huizachal del noreste de México, depositado durante la apertura del Golfo de México; si esto fuera cierto entonces la instauración de la FSM pudiera extenderse hasta tiempos Triásico TardíoJurásico Temprano, por lo cual solamente puede indicarse que estas rocas son de una edad pre-Titoniano. Por otro lado, en la región de Potrero Colorado afloran: a) la parte superior de las capas Tanque Cuatro Palmas (?), b) un paquete conglomerático de $\sim 10 \mathrm{~m}$ de espesor, c) un paquete de arenisca eólica "eolianita" de $191 \mathrm{~m}$ de espesor, que McKee et al. (1990) definieron como capas Colorado, y d) la Formación San Marcos (Figura 2). Finalmente, en Sierra Mojada afloran tres unidades conglomeráticas del Cretácico Inferior, correlacionables con la Formación San Marcos (Figura 2).

\section{Instauración de la falla San Marcos}

Los sedimentos clástico marinos de las capas Tanque Cuatro Palmas acotan la edad pre-Titoniano como mínima para la instauración de la FSM (McKee et al., 1990). Se interpreta que la falla fue activa durante el depósito de las unidades subyacentes (capas Las Palomas y Sierra El Granizo) pero su edad es incierta por carecer de fósiles.

El análisis estructural realizado se concentró en el estudio de las diferentes familias de fallas, así como sobre las geometrías y orientaciones de los pliegues asociados a la traza de la FSM. Las fallas se separaron en familias y/o sistemas característicos dentro de cada nivel estratigráfico. Esto se hizo para establecer con detalle la cinemática de la FSM durante su instauración y los diferentes eventos de reactivación. Con el objetivo de determinar direcciones principales de compresión máxima y mínima para cada uno de los eventos de fallamiento, se calcularon paleotensores de esfuerzos utilizando el programa INVD de Angelier (1990) para cada una de las estaciones de fallas.

El definir la cinemática de la etapa inicial de la FSM fue complicado, debido a que las rocas del basamento PérmicoTriásico que fueron cortadas inicialmente por la FSM, no están expuestas claramente, a lo que se suma que la zona de deformación parece ser muy amplia. Según McKee et al. (1990) existen afloramientos escasos de granitoides del basamento in situ sobre la traza de la FSM, que fueron 


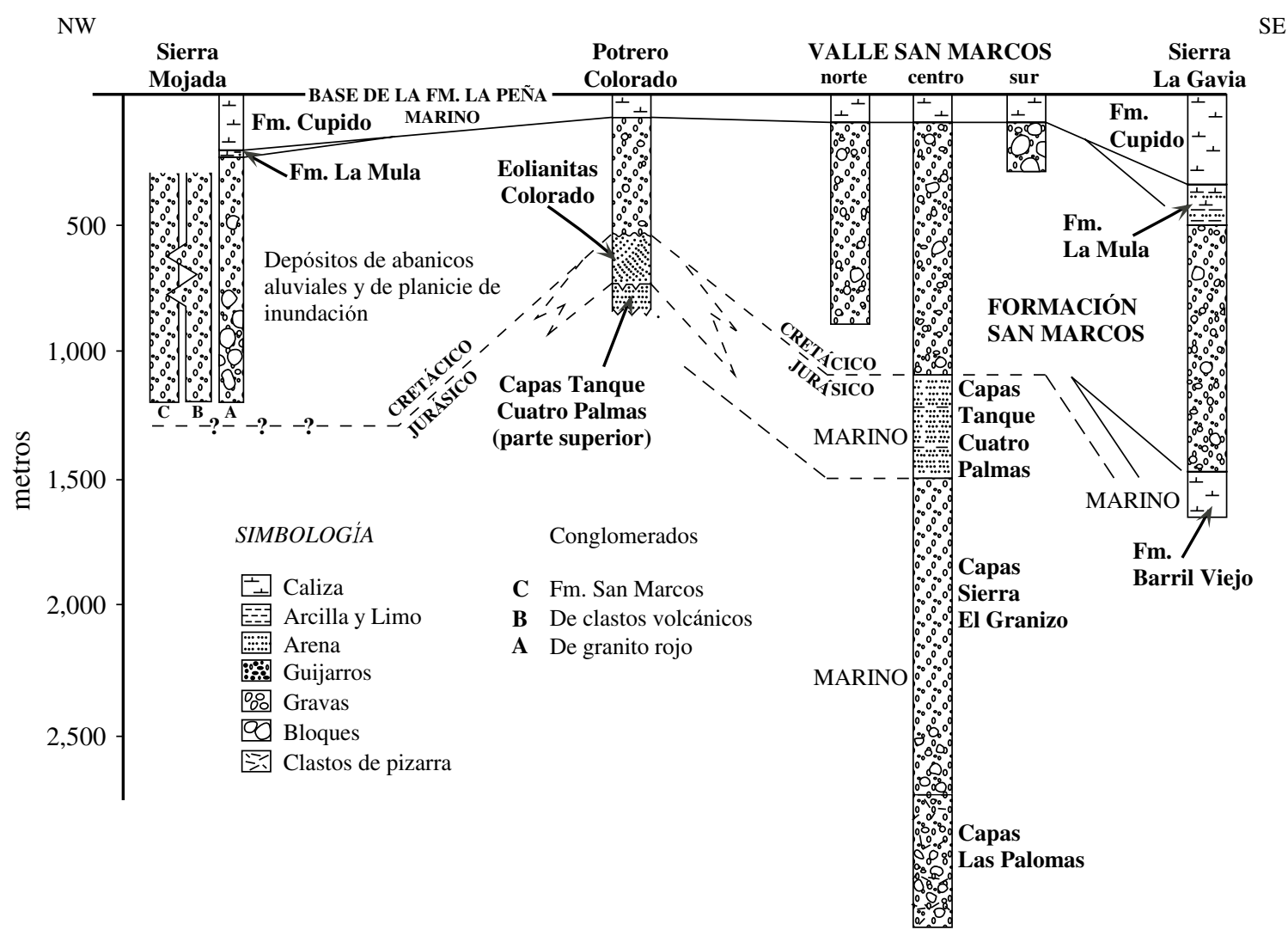

Figura 2. Correlación de los paquetes clásticos depositados en el bloque del bajo al norte de la FSM entre el Jurásico y el Neocomiano (Tomada de McKee et al., 1990).

deformados durante la instauración de la FSM en el VSM. Sin embargo, Molina-Garza et al. (2003) y Arvizu-Gutiérrez (2003), con base en estudios paleomagnéticos, interpretan que estos afloramientos no corresponden a cuerpos in situ del basamento, sino más bien a megabloques derivados del escarpe de la FSM, durante la actividad asociada a su instauración.

Por otro lado, debido a su composición y estructura, las rocas clásticas del Jurásico Superior depositadas sobre el bloque al norte de la FSM sólo muestran evidencias estructurales aisladas de la posible cinemática de la FSM. Aún así, se logró identificar una zona con pliegues y otra con fallas que en primera instancia no descartan la ocurrencia de desplazamientos laterales para el tiempo de instauración de la FSM. Estas evidencias estructurales de campo se describen a continuación

\subsection{Plegamiento del Jurásico Tardío (?) en el valle San Marcos}

En el VSM existe una zona con dos estructuras plegadas orientadas NNW-SSE a N-S con ejes de pliegue buzantes aproximadamente entre $20^{\circ}$ y $30^{\circ}$ hacia el norte (anticlinal y sinclinal; Figura 3). El plegamiento en las rocas jurásicas, junto con las zonas de cizalla de ángulo alto presentes en las rocas sedimentarias marinas del Cretácico, documentan la intensa deformación dentro de la zona afectada por la FSM. Fuera de la zona de cizalla de la FSM el grado de deformación de las rocas clásticas jurásicas y clásticas del Neocomiano, es semejante al observado en la secuencia calcárea del Cretácico Superior. La importancia de las estructuras jurásicas es que están en una zona de doblez de la FSM y corresponden a las únicas macroestructuras plegadas, hasta ahora conocidas, en rocas del Jurásico que afloran sobre la traza de la FSM (Figura 3).

Debido a que el plegamiento y fallamiento se presenta en un área que fue propuesta como una zona de curvatura contractil izquierda jurásica asociada a la FSM (Figura 3; McKee et al., 1990), Arvizu-Gutiérrez (2003) y MolinaGarza et al. (2003) colectaron muestras y realizaron un estudio paleomagnético local que permitió obtener información sobre las rotaciones y posibles tiempos de magnetización en estas estructuras plegadas, así como en afloramientos de rocas graníticas del basamento en el mismo VSM los cuales, de acuerdo con Jones et al. (1982) y McKee et al. (1990), al parecer representan al basamento in situ y contienen evidencias microestructurales que indican una cinemática izquierda generada durante la formación de la FSM.

Los resultados de Arvizu-Gutiérrez (2003) y MolinaGarza et al. (2003) sugieren que los granitoides del Triásico ( $242 \pm 2 \mathrm{Ma}$, edad modelo Rb-Sr en muscovita) que McKee 


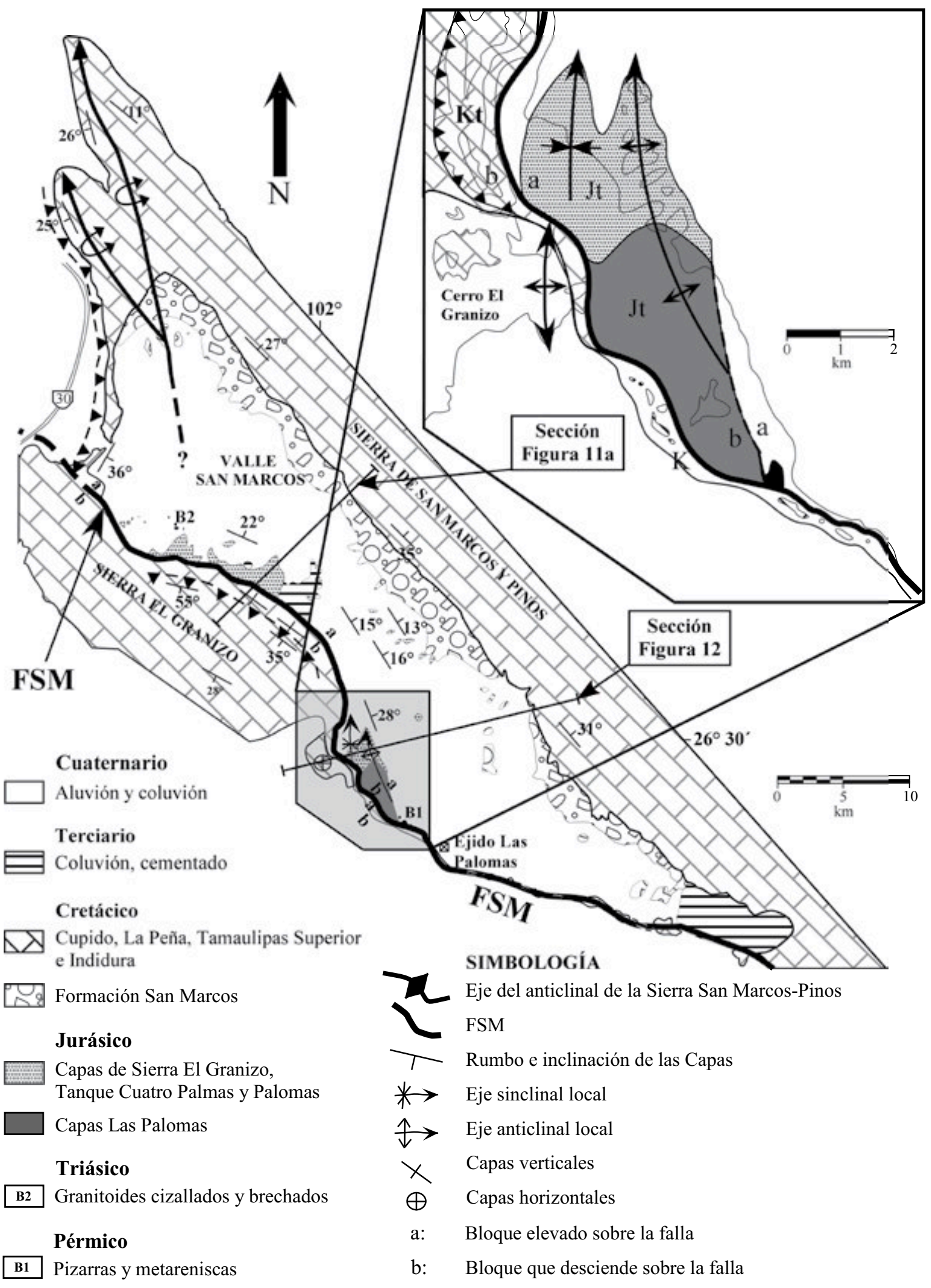

Figura 3. Carta geológica-estructural simplificada del valle San Marcos (ver Figura 1 para su localización). En el recuadro superior derecho se muestra el detalle de las estructuras en la zona de doblez de la falla que fueron estudiadas por Molina-Garza et al. (2003) y Arvizu-Gutiérrez (2003). Nótese la distribución de las fallas que delimitan a estas estructuras, las cuales tienen inclinaciones muy verticales que se discuten en el texto. 
et al. (1990) interpretan como basamento in situ, no pertenecen a un basamento homogéneo. Proponen que deben representar bloques caídos del escarpe de la FSM durante su actividad, apoyados en que los datos no presentan declinaciones ni inclinaciones del Triásico, así como tampoco muestran una consistencia entre ellos.

Por otro lado, para los pliegues desarrollados en las capas Las Palomas en el VSM, establecen que estas estructuras registran una inclinación muy somera de la magnetización, y que al comparar los datos con la curva de vagabundeo polar aparente de América del Norte, éstos indican una rotación horaria entre $80^{\circ}$ y $90^{\circ}$ (Arvizu-Gutiérrez, 2003). Se concluye que la rotación horaria es de carácter local al comparar los polos de las capas Las Palomas con sus correspondientes de la Serie Acatita y la Formación Nazas de edad un poco más antigua (Figura 4); las cuales representan a posiciones cercanas a la esperada para América del Norte sobre el bloque de Coahuila y al sur de este, respectivamente.

Cabe destacar que la rotación horaria en las capas Las Palomas es inconsistente para una zona de curva contractiva izquierda, para cualquier tiempo de deformación, como había sido propuesta por McKee et al. (1990). Una alternativa para la explicación del origen de los pliegues en las rocas jurásicas presentes en el VSM y de su rotación horaria, es que éstos hayan sido desarrollados y rotados como resultado de deformación compleja durante la orogenia Laramide del Paleógeno en la zona. Lo anterior, debido a que se sugiere que la orogenia Laramide del Paleógeno ocurrió en dos fases (Chávez-Cabello, 2005), la más antigua representada por despegues sedimentarios y la más tardía por reactivación inversa de fallas del basamento. Cabe señalar que los pliegues en las rocas jurásicas están delimitados al SW y NE por dos fallas antiguas paralelas a la zona de doblez de la FSM, inclinadas hacia el NNE, que fueron reactivadas con componente inversa durante la fase tardía de la deformación del Paleógeno; son necesarios más estudios estructurales y paleomagnéticos detallados afuera de la zona de doblez de la FSM, para confirmar que la rotación es local, que no está presente en áreas donde la traza de la FSM es cercanamente recta y que ésta haya sido generada durante la deformación Laramide del Paleógeno como aquí se sugiere.

\subsection{Fallamiento del Jurásico Tardío en Potrero Colorado}

La evidencia estructural que aquí se interpreta como producto de deformación durante el Jurásico Tardío, corresponde a fallas con desplazamiento normal orientadas oblicuamente (NW-SE) a la traza principal de la FSM $(\sim \mathrm{E}-\mathrm{W})$ en Potrero Colorado. Las fallas normales están presentes en la secuencia de limolita y arenisca marina de las capas Tanque Cuatro Palmas en Potrero Colorado, así como en la eolianita capas Colorado (Figura 5a) que afloran en el núcleo del anticlinal de la Sierra La Fragua en la localidad de Potrero Colorado (Figura 6). Otra familia de fallas reconocida corresponde a fallas con desplazamiento lateral derecho menor, las cuales retoman o reactivan esencialmente a los planos de las fallas normales preexistentes en la eolianita de las capas Colorado (Figura 5a) y a escasas fracturas escalonadas con cinemática izquierda (Figura 5b). Cabe mencionar que es en Potrero Colorado donde se presentan estructuras claras que documentan actividad de la FSM para el Jurásico Tardío y de su primer evento de reactivación del Neocomiano.

La eolianita capas Colorado muestra estratificación cruzada de gran escala y presenta un espesor de $\sim 200 \mathrm{~m}$ (Charleston, 1973). Sobreyacen a través de un contacto abrupto a un paquete de conglomerado fluvial y arenisca roja de $\sim 10 \mathrm{~m}$ de espesor (Figura 2). Subyacen a través de un contacto erosivo al conglomerado y arenisca de la Formación San Marcos (McKee et al., 1990), que en esta área tiene un espesor de $\sim 500 \mathrm{~m}$, menor que el presente en el VSM (Figura 2). El conglomerado fluvial que subyace a la eolianita, a su vez sobreyace en contacto erosivo también a capas marinas no fosilíferas de limolita y arenisca de cuarzo que presentan un espesor mínimo de $100 \mathrm{~m}$ (Figura 2). Charleston (1973) inicialmente había considerado a la arenisca y limolita como del Cretácico; sin embargo, McKee et al. (1990) las ubicaron posteriormente en el Jurásico

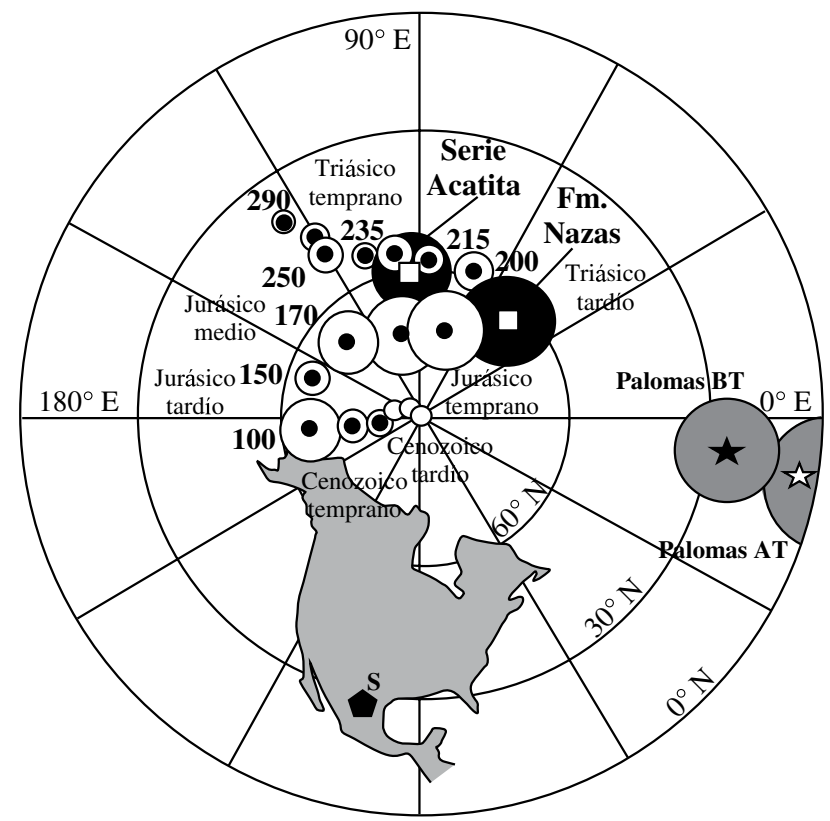

Figura 4. Los círculos blancos corresponden a la curva de vagabundeo polar aparente de referencia para Norteamérica con sus respectivos intervalos de confianza $\left(\mathrm{A}_{95}\right)$. Se indica con numerales la edad de los polos de referencia. Los cuadrados son polos paleomagnéticos para series mesozoicas en el norte de México (Molina-Garza, 2005) e incluyen los intervalos de confianza $\mathrm{A}_{95}$ correspondientes. Las estrellas son los polos para la serie jurásica de las capas Las Palomas in situ (estrella sólida BT, Arvizu-Gutiérrez, 2003) y corregidos por la actitud estructural de las capas(estrella blanca AT); se incluyen los intervalos de confianza del polo representado por el $\mathrm{A}_{95}$. El hexágono (S) marca el sitio de muestreo de las capas Las Palomas en Coahuila. 


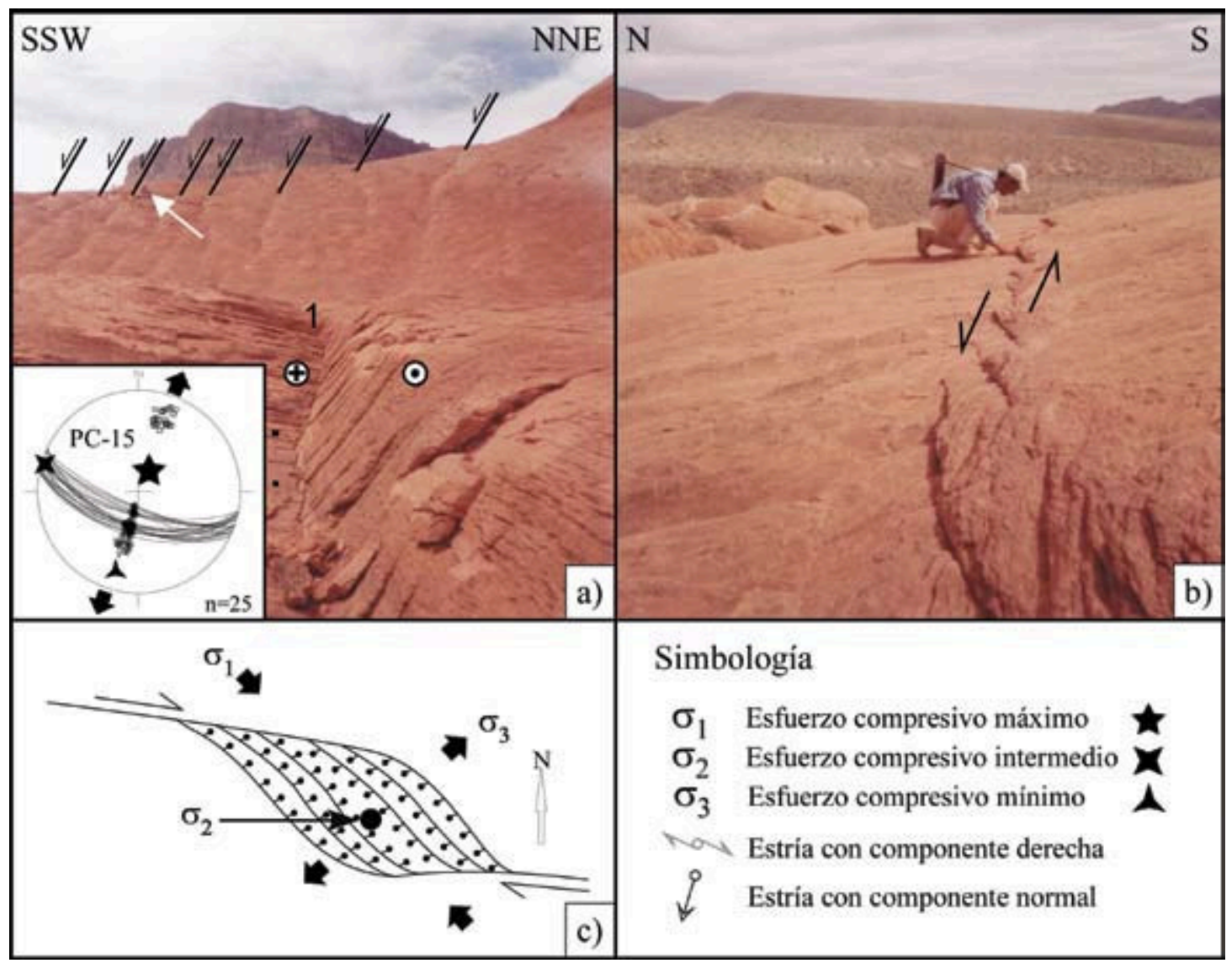

Figura 5. a) En la parte superior se observa un conjunto de fallas con arreglo en dominó. La inclinación de estas estructuras es aquella que se espera en fallas normales, pero el análisis de indicadores cinemáticos indica corrimientos dextrales más jóvenes. Estas relaciones se interpretan como fallamiento normal inicial reactivado como lateral derecho; en la red se aprecia el rumbo, inclinación y las direcciones principales de los esfuerzos calculados para las fallas normales. La flecha blanca señala a una persona como escala en el horizonte, la clave PC-15 indica el número de la estación de fallas (Tabla 1, tensor de esfuerzo calculado) y $\mathrm{n}$ : indica el número de datos de falla. b) fracturas escalonadas que indican una cinemática izquierda local. Para algunos casos de las fallas laterales, se infirieron direcciones posibles de estrías con base en la orientación de los escalones de falla, por lo que los cálculos de las direcciones de los esfuerzos deben ser tomados con reserva y c) modelo de curva contráctil aplicable para las fallas normales y laterales derechas jurásicas de Potrero Colorado. La simbología que se muestra en esta figura aplica para todas las redes que se presentan en este trabajo.

Superior y las correlacionaron con las capas Tanque Cuatro Palmas descritas para el área de VSM (Figura 2). Estas capas, en Potrero Colorado, al parecer muestran variaciones verticales hacia ambientes continentales ya que en este trabajo fueron reconocidas grietas de desecación con marcas de lluvia, restos de plantas e icnofósiles que pudieran ser huellas de dinosaurio.

Con base en lo descrito por McKee et al. (1990), es claro que la inferencia de que la eolianita sea del Jurásico Superior se apoya en que subyace a la Formación San Marcos, la cual descansa sobre las capas Tanque Cuatro Palmas que contienen amonites del Titoniano en el VSM. La importancia estructural de las capas Tanque Cuatro Palmas y capas Colorado, que subyacen a la Formación San Marcos en Potrero Colorado, radica en que presentan fallas con indicadores cinemáticos como escalones de falla y fracturas Riedel que permiten interpretar la cinemática del fallamiento del Jurásico Tardío en la parte central de Coahuila. Es importante aclarar que las superficies de falla en ocasiones no muestran superficies estriadas, debido a que las areniscas son poco cementadas; en muchos de los casos la dirección y el sentido del movimiento fue inferido con base en el arreglo de los escalones de falla y de las fracturas Riedel reconocidas en los planos de falla. Por otro lado, es importante señalar que las fallas son exclusivas de estas capas ya que no afectaron a las rocas más jóvenes. Un dato adicional importante es que las fallas laterales derechas que retoman a planos de falla normal en las rocas jurásicas, no están presentes dentro de la Formación San Marcos; es decir, son más antiguas que el depósito de la Formación San Marcos.

La limolita y arenisca del Jurásico Superior de Potrero Colorado, que subyacen al paquete de conglomerado y a la eolianita, al igual que esta última presenta el mismo sistema de fallas normales (Figura 7a). Es importante mencionar que parte, sino es que todo, el depósito de la limolita y la arenisca de las capas Tanque Cuatro Palmas de Potrero Colorado, ocurrió durante fallamiento normal y lateral derecho acti- 


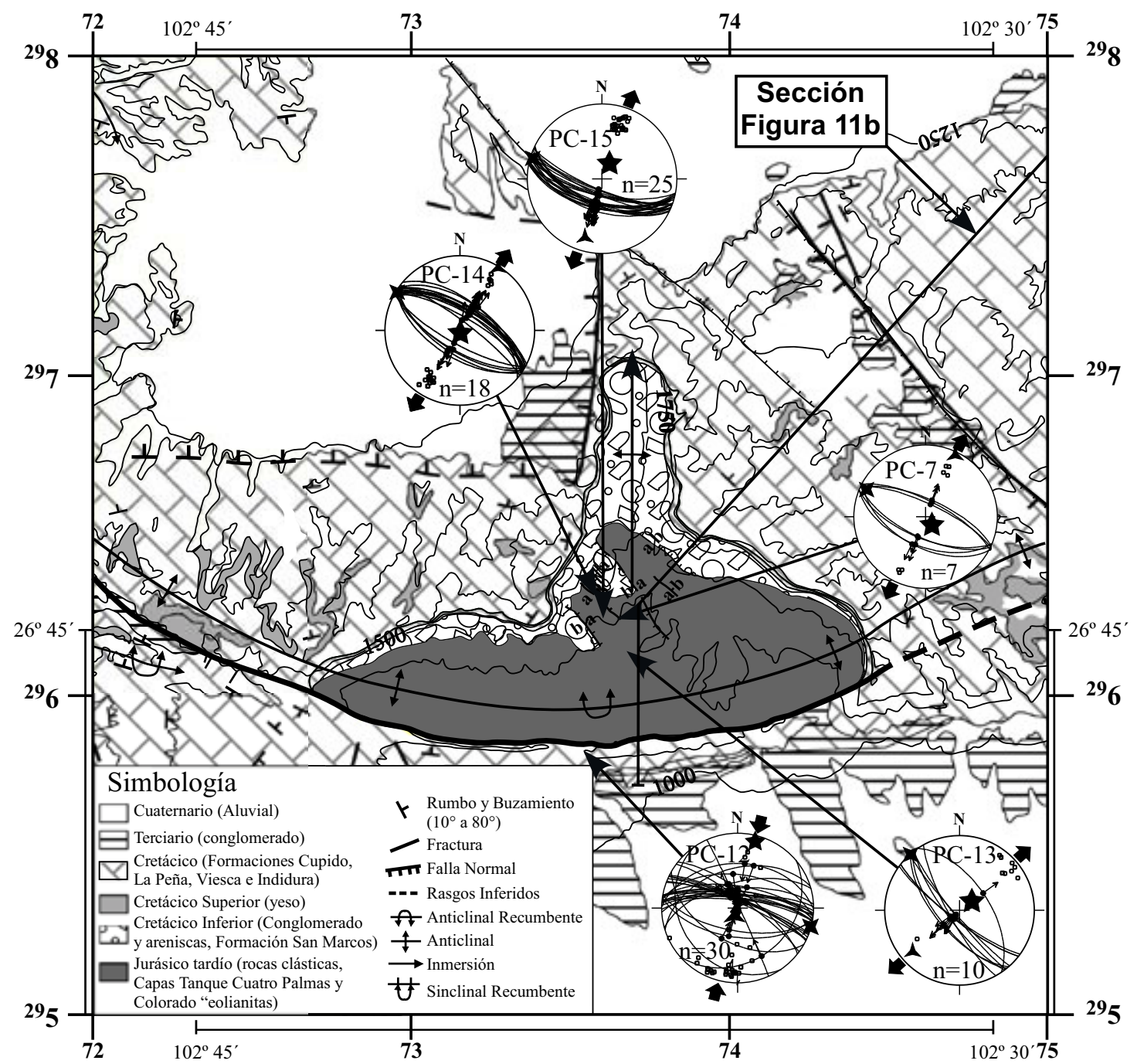

Figura 6. Mapa geológico simplificado de Potrero Colorado empleado para ubicar las estaciones de fallas documentadas en esta zona. La localización de esta área se muestra en la Figura 1.

vo. Lo anterior se corroboró al identificar en muchos de los casos espesores mayores de sedimentos en los bloques hundidos de las fallas (Figura 7a); en esta misma figura se observa un paleorelive en limolita litificada, cortada por fallas normales, que fue cubierto por arenisca de cuarzo que muestra rasgos de asentamiento local de los sedimentos. Las fallas antiguas en la limolita, al parecer, propagaron desplazamientos menores sobre la arenisca después de su depósito (Figura 7a). Otro rasgo muy característico es que varias de las zonas de falla sinsedimentaria muestran rasgos de licuefacción (i.e. caso de fallas laterales derechas), lo que apoya la hipótesis de que el fallamiento ocurrió aún cuando parte de los sedimentos presentaban saturación de agua o escasa litificación, esto porque se observan zonas de deformación con mezcla de sedimentos sin rasgos de deformación frágil (Figura 7b). Las fallas que principalmente muestran rasgos de licuefacción corresponden a fallas laterales derechas que al parecer actuaron alternadamente con las fallas normales (Figura 7b).
En la eolianita se presentan rasgos bien definidos que detallan la geometría tridimensional de las fallas e indicadores cinemáticos del fallamiento en el Jurásico Tardío. En éstas se identificó un fallamiento normal con arreglo en dominó, con rumbo NW-SE e inclinación hacia el SW (Figura 5a); lo que llama la atención de estos planos de falla es que la zona de falla debió ser cementada y posteriormente reactivada, ya que las fallas presentan escalones de falla con fracturas Riedel bien desarrolladas que indican desplazamiento menor de tipo lateral derecho (Figura 5a). Además, en la eolianita también se reconocieron varias fracturas menores con arreglo escalonado (Figura $5 b$ ), que sugieren una cinemática izquierda local; sin embargo, la cinemática derecha en las fallas es ampliamente predominante en la zona.

La familia de fallas laterales derechas producto de la reactivación de fallas normales localmente más antiguas (Figura 5a), no puede ser utilizado en el sentido estricto para calcular un tensor de esfuerzos debido a que son fallas que 
retomaron planos preexistentes. Sin embargo, se infiere que un acortamiento en la zona NW-SE pudo haber generado la reactivación de las fallas normales con componente lateral derecha (Figuras 5 a y 5c). Los planos normales reactivados como fallas laterales ocurren abundantemente en la eolianita capas Colorado y en el paquete de arenisca y limolita de las capas Tanque Cuatro Palmas. Adicionalmente, cerca del afloramiento con fallas en arreglo tipo dominó, se identificó una pared de roca dentro del paquete de eolianita que muestran el desarrollo de estructuras tipo fosas y pilares, cubiertos por sedimentos eólicos más jóvenes, los cuales se consideran en este trabajo como una evidencia más de que la zona experimentó extensión en el Jurásico Tardío en dirección NNE-SSW (Figuras 8a y 8b).

La importancia del afloramiento de la Figura 8, al igual que en la limolita y arenisca de cuarzo más antiguas, es que muestra que el fallamiento y sedimentación fueron contemporáneos, ya que las fallas son sepultadas por sedimentos más jóvenes en la secuencia, y no cortan el contacto superior de esta unidad con la Formación San Marcos. La imagen en dos dimensiones del fallamiento normal conjugado observado en este afloramiento sugiere, en primera instancia, que ocurrió compresión mínima en dirección NNE-SSW a NE-SW. Sin embargo, existe un número importante de fallas laterales derechas que cortan o retoman a los planos con arreglo conjugado de fallamiento normal tanto en la limolita y arenisca de las capas Tanque Cuatro Palmas como en la eolianita de las capas Colorado. Lo anterior sugiere que el fallamiento en el Jurásico Tardío fue complejo y que involucró desplazamiento normal primero, litificación en parte de estas zonas de falla, y fallamiento lateral derecho alternado con desplazamientos de escala centimétrica a métrica a través de estas discontinuidades, desarrollando en su etapa temprana fracturas Riedel. La integración de estos dos sistemas de fallas, operando alternadamente, puede ser explicado como resultado de la operación de una zona de curvatura contráctil sobre la traza de la FSM para el área de Potrero Colorado durante un tiempo pre-Titoniano o quizás en el mismo Jurásico Tardío, en el que pudo ocurrir compresión máxima $\sim \mathrm{NW}-\mathrm{SE}$ y compresión mínima NESW (Figuras 5c y 6).

Las relaciones entre las fallas (normales y laterales derechas) documentadas en Potrero Colorado para el Jurásico, se consideran en este trabajo como evidencias de mayor peso para sugerir que es más probable que, en un tiempo pre-Titoniano o inclusive en el mismo Jurásico Tardío, esta zona pudo haber operado como una curva contráctil derecha sobre la traza de la FSM. Esta sugerencia se apoya principalmente en que las evidencias de estructuras sedimentarias primarias claras como lo es la estratificación, y de las fallas reconocidas en Potrero Colorado, tienen prioridad en la interpretación con respecto a las estructuras sedimentarias primarias poco claras y a la ocurrencia de pliegues en VSM, que sugerirían en primer instancia que esta zona podría corresponder a una zona de curvatura contráctil izquierda, es decir totalmente opuesta a lo que se observa en Potrero Colorado.

Es importante mencionar que el doblez de la FSM cerca de Potrero Colorado es similar al presente en VSM. Sin embargo, las fallas normales y laterales derechas presentes en Potrero Colorado contrastan abruptamente con los pliegues observados en la zona de doblez de la falla en VSM. Por lo anterior, sugerir un origen de estas estructuras bajo las mismas condiciones de esfuerzos en la corteza para un tiempo específico es incongruente. En este trabajo se considera que el fallamiento normal y lateral derecho, que actuó alternadamente durante la sedimentación de las capas Tanque Cuatro Palmas y la eolianita capas Colorado,

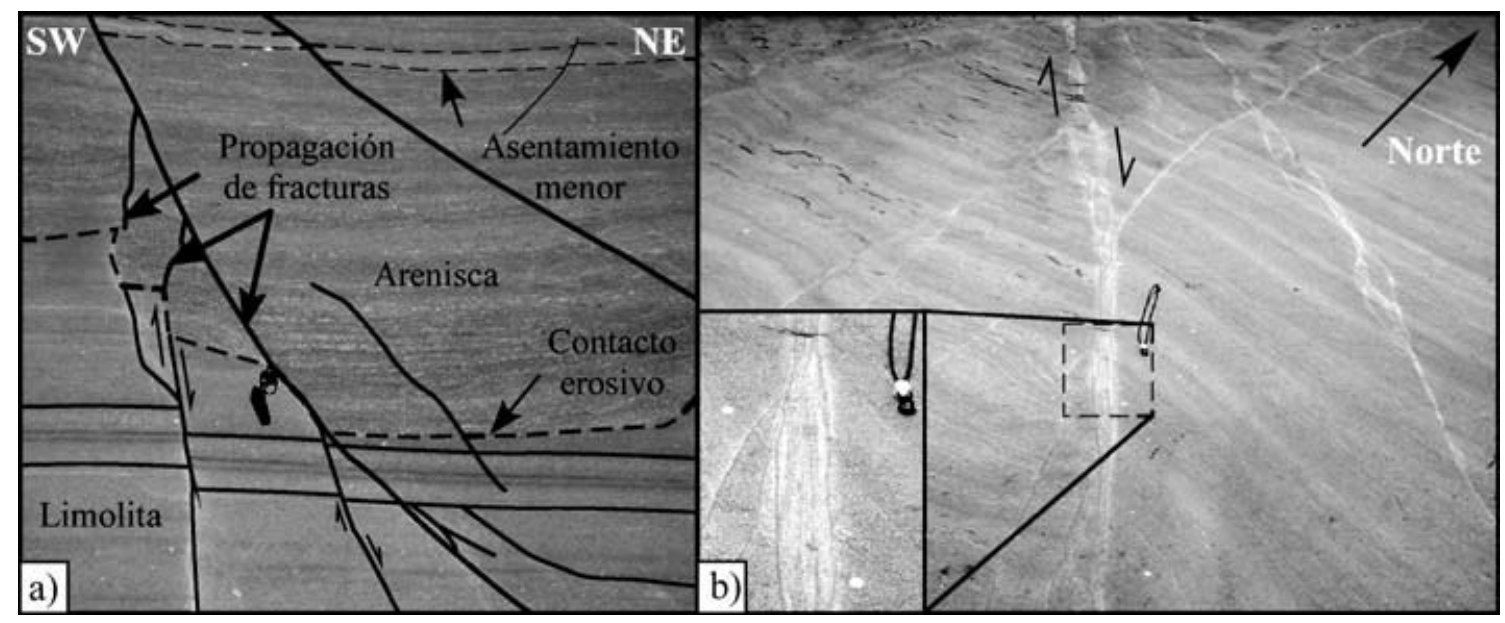

Figura 7. a) Fallas normales que cortan el contacto entre limolita y arenisca de cuarzo de las capas Tanque Cuatro Palmas en Potrero Colorado; nótese que la arenisca fue depositada después del fallamiento normal y posteriormente ocurrió la propagación de fracturas menores dentro de la arenisca a partir de las fallas normales más antiguas, así como asentamientos menores de los sedimentos; cerca del centro de la fotografía se muestra una navaja como escala. b) Falla lateral derecha en la limolita y arenisca de cuarzo de las capas Tanque Cuatro Palmas que muestra que la falla al perecer ocurrió aun cuando los sedimentos estaban saturados de agua o presentaban baja litificación. 
en Potrero Colorado, son más concluyentes en cuanto al tiempo y cinemática de la deformación, que lo que pueden documentar las estructuras observadas en VSM. Con base en lo anterior, se sugiere que la FSM puedo haber actuado con una componente lateral derecha menor en un tiempo pre-Neocomiano; mientras que las estructuras plegadas con rotación horaria de 80 a $90^{\circ}$ (Arvizu-Gutiérrez, 2003; Molina-Garza et al., 2003), presentes en la zona de doblez de la FSM en VSM, se sugiere pudieron haber sido producto de acortamiento y rotación durante la deformación laramídica compleja que experimentó la zona en el Paleógeno

\section{Reactivaciones de la falla San Marcos}

\subsection{Primera etapa: reactivación del Cretácico Temprano}

El primer evento de reactivación de la FSM ocurrió en el Neocomiano y fue documentado por McKee et al. (1990) a lo largo de toda la traza de la FSM por la ocurrencia de un nuevo paquete clástico que, a diferencia de la secuencia pre-Neocomiano del VSM, éste es de ambiente continental y corresponde a la Formación San Marcos. La Formación San Marcos es predominantemente fluvial y también existen depósitos eólicos a fluviales en su base en Potrero Colorado; el cambio de ambiente de depósito en el Neocomiano también es evidente por la ocurrencia de depósitos aluviales y de planicie de inundación en Sierra Mojada (Figura 2). Por el cambio drástico de ambiente de depósito, McKee et al. (1990) interpretaron que la FSM debió tener una reactivación con componente normal importante a escala regional, sugiriendo un ajuste isostático como causa potencial. Otro dato importante es que este evento coincide con lo que Goldhammer (1999) y Eguiluz de Antuñano (2001) definen como un cambio eustático global reconocido en todo el noreste de México (alrededor del bloque de Coahuila y dentro de la misma cuenca de Sabinas), el cual define el límite de una supersecuencia deposicional de segundo orden (Goldhammer, 1999). Nuevamente en este trabajo se documentaron fallas normales que actuaron en el Neocomiano, no reportadas aún en la literatura, que apoyan la ocurrencia de levantamientos importantes que alteraron drásticamente la sedimentación en la parte central de Coahuila.

Al igual que el fallamiento normal y lateral derecho del Jurásico Tardío, las fallas normales del Neocomiano asociadas al depósito de la Formación San Marcos fueron también solamente documentadas en Potrero Colorado. Lo anterior, porque en las localidades de Sierra Mojada y VSM no está expuesto el contacto entre las rocas del Jurásico Superior y el conglomerado de la Formación San Marcos como se observa en Potrero Colorado (Figura 9).

Se revisó en detalle el contacto entre la eolianita capas Colorado y la Formación San Marcos, observándose fallas normales con saltos de decenas de metros (Figura 9a), hasta unos pocos metros (Figura 9b). También se encontró una familia de fallas normales con arreglo en dominó con

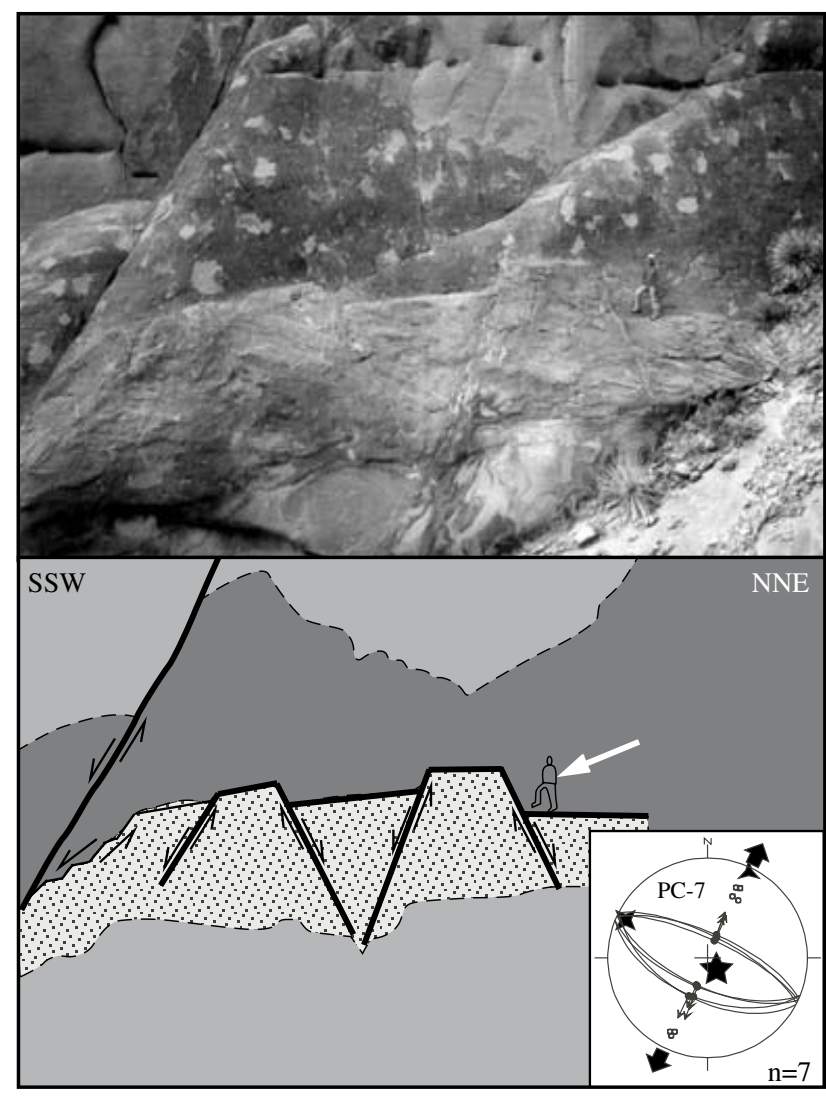

Figura 8. Fosas y pilares en las capas Colorado del Jurásico Superior en Potrero Colorado. En la fotografía superior se muestra el afloramiento, en la parte inferior el dibujo muestra las relaciones de contacto y fallas reconocidas $\mathrm{y}$, en la parte inferior derecha, la red estereográfica que muestra la dirección de compresión mínima NNE para estas fallas normales. Nótese que algunas de las fallas que forman un arreglo de fosas y pilares no cortan los estratos más jóvenes, mientras que la falla mayor al SSW desplaza a toda la secuencia. La falla mayor al SSW corresponde a una falla neocomiana que corta el contacto entre la eolianita y la Formación San Marcos, mientras que las fallas menores, en el centro de la fotografía, se interpretan como evidencias de fallamiento sinsedimentario del Jurásico Tardío. La flecha blanca en el dibujo inferior señala a una persona como escala. Los tonos diversos en el dibujo muestran contactos internos entre diferentes direcciones de estratificación cruzada en las capas Colorado. PC-7 indica la estación de fallas y $\mathrm{n}$ el número de datos colectados en este sitio.

el bloque hundido hacia el suroeste (Figura 9c). Algo muy importante, que fue corroborado en campo, es que estas fallas que cortan claramente el contacto entre la eolianita y el paquete clástico de la Formación San Marcos, no cortan el contacto superior de la Formación San Marcos con la Formación Cupido, la cual está compuesta por carbonatos marinos de facies arrecifales del Hauteriviano-Barremiano (Figuras 6 y 9), debido a que las fallas fueron sepultadas durante el depósito de la parte superior de la Formación San Marcos. Por lo anterior, estas rocas restringen el tiempo de desplazamientos normales sobre la FSM al Neocomiano.

Las fallas normales con rumbo NW-SE que se observaron cortando el contacto entre las capas Colorado (eolianita) y la Formación San Marcos, definen direcciones principales de compresión mínima NE-SW (Figura 9; estaciones PC-13 


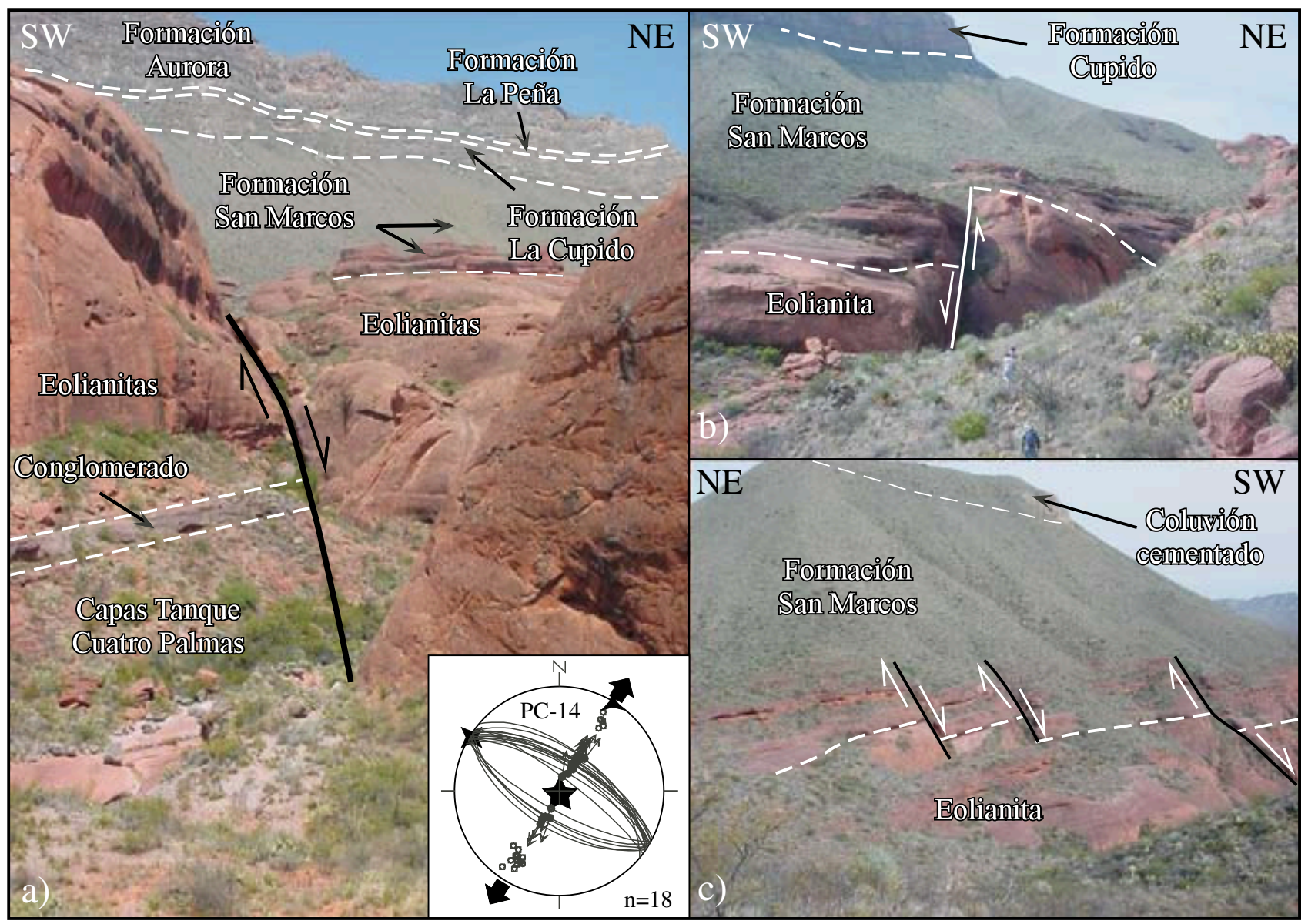

Figura 9. Fallas que cortan el contacto entre las capas Colorado y la Formación San Marcos al noroeste de Potrero Colorado. a) falla normal con salto de falla superior a $10 \mathrm{~m}$ y bloque caído hacia el NE, b) falla normal con bloque caído hacia el SW; esta falla con la de "a" forman una fosa tectónica y, c) arreglo de fallas normales en dominó con saltos de pocos metros y bloques caídos hacia el SW. Ninguna de estas fallas corta el contacto entre las Formaciones San Marcos-Cupido. La red estereográfica en "a" muestra las direcciones de compresión mínima obtenidas para este grupo de fallas. Las líneas blancas punteadas delimitan contactos.

y 14; Figura 6 y Tabla 1). Con base en lo anterior, se fortalece la interpretación de que hubo un período de extensión en el Cretácico Temprano, que hizo actuar a la FSM como una falla normal, tal y como sugieren McKee et al. (1990) con base en su estudio estratigráfico. Con lo anterior, se han documentado los elementos estructurales que fortalecen la hipótesis de un evento de extensión importante que contribuyó al crecimiento de la cuenca de Sabinas durante el Neocomiano.

\subsection{Segunda etapa: reactivación Laramide del Paleógeno}

Las estructuras que documentan la deformación del Paleógeno son muy comunes sobre la traza de la FSM y dentro de todo el CPC (Figura 1). Este evento de deformación corresponde a la orogenia Laramide durante la cual la FSM tuvo una segunda reactivación importante, pero ahora con una componente inversa. Durante este período de reactivación de la FSM, otras fallas secundarias a la
FSM fueron también invertidas así como la misma cuenca de Sabinas.

\subsubsection{Plegamiento Laramide}

El plegamiento de las rocas sedimentarias marinas mesozoicas sobre la traza de la FSM es complejo, ya que existen cambios fuertes en la orientación de ejes de pliegues, los cuales presentan arreglos cercanamente perpendiculares entre sí (Figura 10). En la zona se presentan casi exclusivamente anticlinales tipo drape (Figuras 10, 11 a y 11b). Una excepción existe al nor-noroeste del VSM, la Sierra de San Marcos Pinos está compuesta por dos anticlinales que pasan de ser anticlinales inclinados a ligeramente recostados hacia el WSW, los cuales contienen un sinclinal apretado; particularmente estos anticlinales indican transporte tectónico hacia el WSW, presentan inmersión hacia el NNW y unen sus ejes para formar una sola estructura en dirección SSE hacia el VSM, donde el núcleo del anticlinal está erosionado exponiendo principalmente a rocas de la Formación San Marcos (Figura 3). 
Tabla 1. Valores de las componentes principales de los tensores de esfuerzos determinados por la técnica de inversión de datos de estrías de falla utilizando el programa INVD de Angelier (1990). Los datos de estrías fueron colectados en estructuras en o cerca de la traza de la FSM.

\begin{tabular}{|c|c|c|c|c|c|c|c|c|c|c|c|}
\hline Localidad & Formación & Tipo de falla & Estación & $\mathrm{T}$ & $\sigma 1$ & $\sigma 2$ & $\sigma 3$ & $\phi$ & $\mathrm{N}$ & RUP & Q \\
\hline$\overline{\mathrm{PC}}$ & СТCP & Normal & PC-13 & 1 & $73 / 051$ & $01 / 319$ & $17 / 228$ & 0.267 & 10 & 21 & $\overline{\mathrm{A}}$ \\
\hline $\mathrm{PC}$ & $\mathrm{CC}$ & Normal & PC-15 & 1 & $71 / 019$ & $04 / 289$ & $18 / 199$ & 0.024 & 25 & 10 & A \\
\hline $\mathrm{PC}$ & $\mathrm{CC}$ & Normal & PC-7 & 1 & $78 / 143$ & $10 / 295$ & $05 / 026$ & 0.840 & 7 & 30 & A \\
\hline $\mathrm{PC}$ & $\mathrm{CC}-\mathrm{SM}$ & Normal & PC-14 & 2 & $87 / 173$ & $02 / 301$ & $02 / 031$ & 0.766 & 18 & 27 & A \\
\hline $\mathrm{PC}$ & $\mathrm{TS}$ & Inversa & PC-12 & 3 & $16 / 012$ & $02 / 102$ & $74 / 199$ & 0.673 & 30 & 28 & A \\
\hline VSM & TS & Inversa & LP-1 & 3 & $12 / 014$ & $03 / 105$ & $78 / 208$ & 0.621 & 29 & 33 & A \\
\hline VSM & Indidura & Inversa & $\mathrm{CG}$ & 3 & $03 / 036$ & $06 / 306$ & $83 / 150$ & 0.559 & 22 & 24 & A \\
\hline VSM & TS & Inversa & SG & 3 & $16 / 191$ & $13 / 284$ & $69 / 051$ & 0.623 & 24 & 38 & A \\
\hline VSM & Cupido & $\begin{array}{l}\text { Lateral/ } \\
\text { Inversa }\end{array}$ & SMM & 3 & $05 / 296$ & $25 / 029$ & $64 / 196$ & 0.687 & 10 & 46 & B \\
\hline VSM & Cupido & Inversa & FCW & 3 & $05 / 287$ & $13 / 018$ & $76 / 175$ & 0.730 & 8 & 9 & A \\
\hline Sierra Mojada & La Mula & Inversa Oblicua & SM-2 & 3 & $00 / 234$ & $23 / 324$ & $67 / 144$ & 0.628 & 41 & 31 & A \\
\hline Sierra Mojada & La Mula & Inversa Oblicua & SM-4 & 3 & $04 / 069$ & $15 / 338$ & $74 / 175$ & 0.831 & 36 & 34 & A \\
\hline Delicias & Las Uvas-Basamento & Lateral & D-1 & 4 & $07 / 077$ & $52 / 177$ & $37 / 342$ & 0.243 & 11 & 23 & A \\
\hline Tetillas & Unidad Externa & Lateral & LT-1 & 4 & $08 / 265$ & $70 / 152$ & $18 / 358$ & 0.651 & 9 & 32 & A \\
\hline Tetillas & Unidad Externa & Lateral & LT-2 & 4 & $27 / 063$ & $04 / 160$ & $45 / 251$ & 0.670 & 11 & 40 & $\mathrm{~B}$ \\
\hline Delicias & Las Uvas-Basamento & Normal & D-2 & 5 & $70 / 328$ & $11 / 090$ & $16 / 184$ & 0.296 & 23 & 38 & $\mathrm{~B}$ \\
\hline Tetillas & Unidad Externa & Normal & LT-3 & 5 & $67 / 355$ & $15 / 227$ & $17 / 132$ & 0.285 & 17 & 32 & B \\
\hline Tetillas & Unidad Externa & Normal & LT-4 & 5 & $72 / 020$ & $10 / 141$ & $15 / 234$ & 0.342 & 29 & 25 & B \\
\hline
\end{tabular}

T: Cronología del fallamiento (1: Jurásico Tardío, lateral izquierdo neoformado, 2: Cretácico Temprano, normal neoformado, 3: Paleógeno, inverso heredado durante el evento Laramide, 4: Terciario medio a tardío, lateral izquierdo heredado); $\sigma_{1}, \sigma_{2}$ y $\sigma_{3}$ : ejes principales del tensor de esfuerzo (inmersión/rumbo en grados); $\varphi$ : relación $\left(\sigma_{2}-\sigma_{3}\right) /\left(\sigma_{1}-\sigma_{3}\right)$; N: Número de datos; RUP: Valor promedio en \% del estimador de coherencia del programa de Angelier , para datos con RUP<75\%; Q: Calidad (A: Bueno, B: Regular, C: Pobre). TCP: capas Tanque Cuatro Palmas, CC: capas Colorado, SM: San Marcos y TS: Tamaulipas Superior.

Se interpreta que el eje del anticlinal de la Sierra San Marcos Pinos fue truncado en su extensión SSE por deformación asociada con la reactivación inversa de la FSM, en la fase tardía de la deformación Laramide durante el Paleógeno (Figura 3; Chávez-Cabello, 2005). Detalles sobre el origen y estilos de deformación de la primera fase de la deformación Laramide en la zona están fuera del alcance de este trabajo, por lo que se citan sólo las relaciones fundamentales de corte entre las estructuras, haciéndose énfasis únicamente sobre el tipo de movimiento de la FSM durante este tiempo y las estructuras que generó.

La Sierra El Granizo está compuesta por un apilamiento de rocas calcáreas del Cretácico Superior controladas por pliegues por doblez de falla con rumbo WNW que indican transporte tectónico hacia el NNE, correspondientes a la primera fase de deformación en la zona, los cuales al igual que el anticlinal de la Sierra San Marcos Pinos fueron cortados durante la reactivación inversa de la FSM (ChávezCabello, 2005), yuxtaponiendo rocas clásticas del Jurásico con rocas del Cretácico Superior de la Sierra El Granizo (Figuras 3, 11a y 12). La reactivación inversa de la FSM habría generado un basculamiento de $\sim 30^{\circ}$ hacia el noreste de toda la secuencia jurásica y cretácica dentro del VSM y la Sierra de San Marcos Pinos al noreste, respectivamente (Figuras 3, 11a y 12). Además, cizalla simple intensa entre las rocas jurásicas y cretácicas en la parte noreste de la Sierra
El Granizo, provocando arrastre y basculamiento de toda la secuencia hacia el suroeste (Figura 11a).

Por otro lado, la Sierra La Fragua se caracteriza por ser un anticlinal asimétrico (tipo drape fold; Figura 11b), poco erosionado de su núcleo y con un rumbo aproximado WNW-ESE. Su flanco sur, flanco frontal del pliegue, cambia de inclinación de $30^{\circ} \mathrm{S}$ en el oriente hasta vertical o incluso invertido en la entrada de Potrero Colorado, al occidente. Este flanco del pliegue es un flanco complejo ya que, al igual que la Sierra El Granizo, presenta fallas y pliegues por doblez de falla menores que duplican localmente la secuencia, pudiendo observarse estas duplicaciones en el cañón El Mimbre (Figura 10b). Las fallas y pliegues dentro de este flanco indican transporte tectónico hacia el NNE y son interpretados como producto de la fase temprana de la deformación Laramide en la zona (Chávez-Cabello, 2005). El flanco norte del anticlinal de la Sierra La Fragua se inclina suavemente hacia el NNE $\left(\sim 15^{\circ}\right)$. El núcleo de la estructura está parcialmente expuesto en Potrero Colorado, donde afloran arenisca y limolita correlacionables con las capas Tanque Cuatro Palmas del Jurásico Superior del VSM, siendo éstas las rocas más antiguas (McKee et al., 1990).

En Sierra Mojada la estructura es más compleja. La Sierra Planchada forma el flanco noreste de un anticlinal con buzamiento moderado hacia el noreste $\left(<30^{\circ}\right)$, en la parte norte de la localidad de Sierra Mojada. Por otro lado, el 


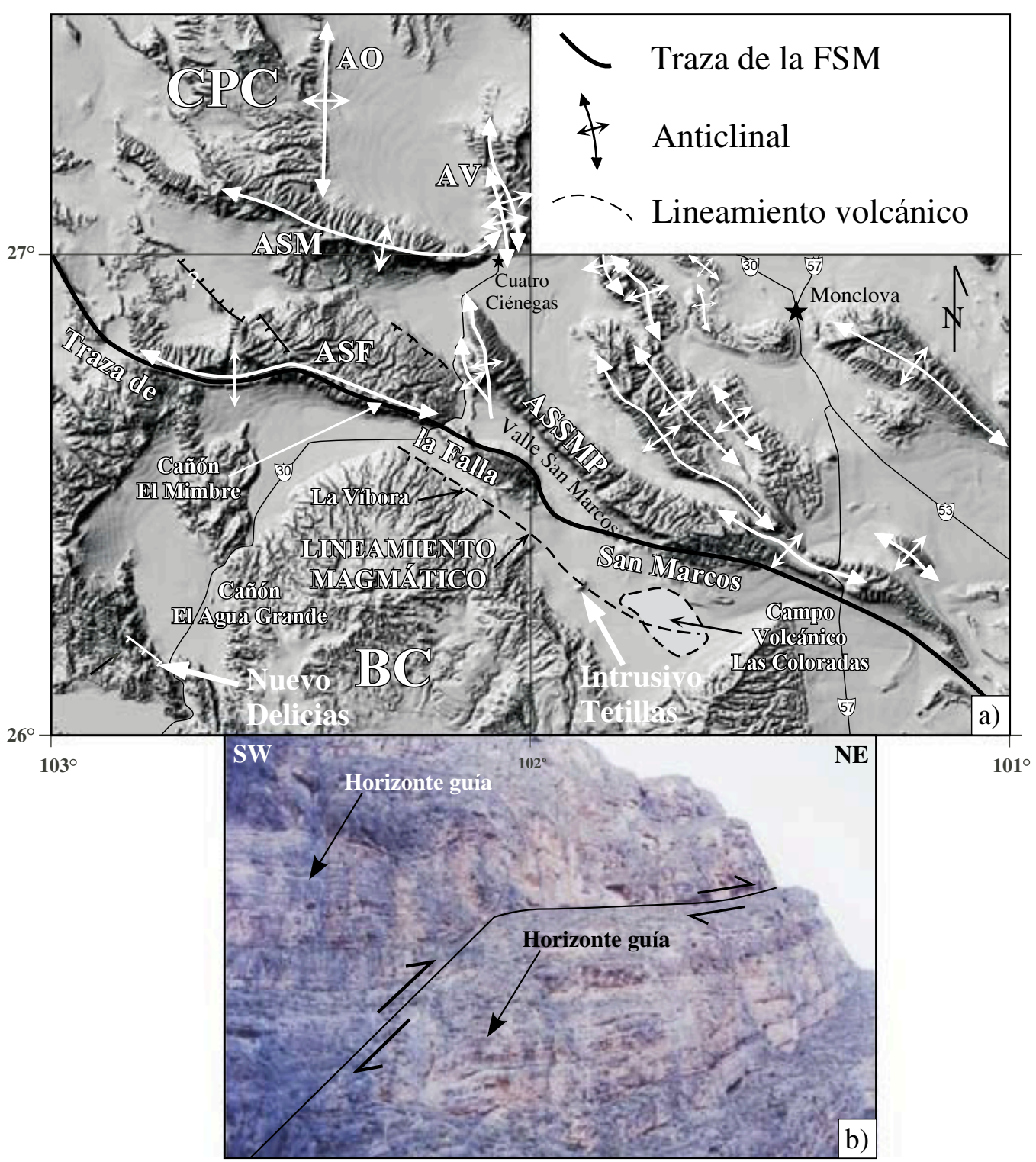

Figura 10. Arreglo casi perpendicular de ejes de pliegues en la parte suroeste del Cinturón Plegado de Coahuila (CPC). La línea punteada subparalela a la FSM al sur de ésta, indica el lineamiento magmático al sur de la FSM. Este se obtiene al unir el cuello volcánico La Víbora, el intrusivo Las Tetillas y el campo volcánico Las Coloradas. Se desconoce la edad isotópica de estos cuerpos magmáticos, pero se cree que pueden ser del Plioceno con base en el nivel de erosión observado. Una excepción notable es el intrusivo Las Tetillas que se considera del Eoceno tardío. ASF: Anticlinal Sierra La Fragua, ASSMP: Anticlinal Sierra San Marcos Pinos, ASM: Anticlinal Sierra La Madera, AO: Anticlinal de Ocampo, AV: Anticlinal La Virgen, y BC: Bloque Coahuila.

flanco suroeste de la estructura anticlinal, compuesto por la Sierra Mojada, presenta fallamiento intenso y cabalgamiento de la secuencia del Cretácico Inferior (conglomerado de la Formación San Marcos, lutita y arenisca de la Formación La Mula y caliza de la Formación Cupido) sobre el Cretácico Superior (Formación Tamaulipas Superior; Figura 11c tomada de McKee et al., 1990). Sin duda, es necesario un trabajo de campo más detallado para definir con certeza las relaciones estructurales y establecer la geometría de la estructura plegada presente en Sierra Mojada, Coahuila.

Los anticlinales de la Sierra La Fragua y de San Marcos Pinos, y muy probablemente la estructura en Sierra Mojada, corresponden a plegamientos complejos formados en dos fases durante el evento orogénico laramídico. En general, las sierras La Fragua y San Marcos Pinos parecen ser anticlinales/monoclinales tipo drape en los que el cambio de inclinación entre los flancos ocurre de forma abrupta, desarrollándose en un espacio muy estrecho un flanco vertical, mientras que el otro flanco tiene inclinaciones muy suaves y constituye la mayor parte de la estructura (Figura 11a y 11b). Los pliegues tipo drape se forman durante la inversión de fallas de basamento (Harding, 1985; Buchanan y McClay, 1991). En el caso de estudio, las fallas antiguas del basamento y de las rocas jurásicas al parecer acomodaron des- 
a)
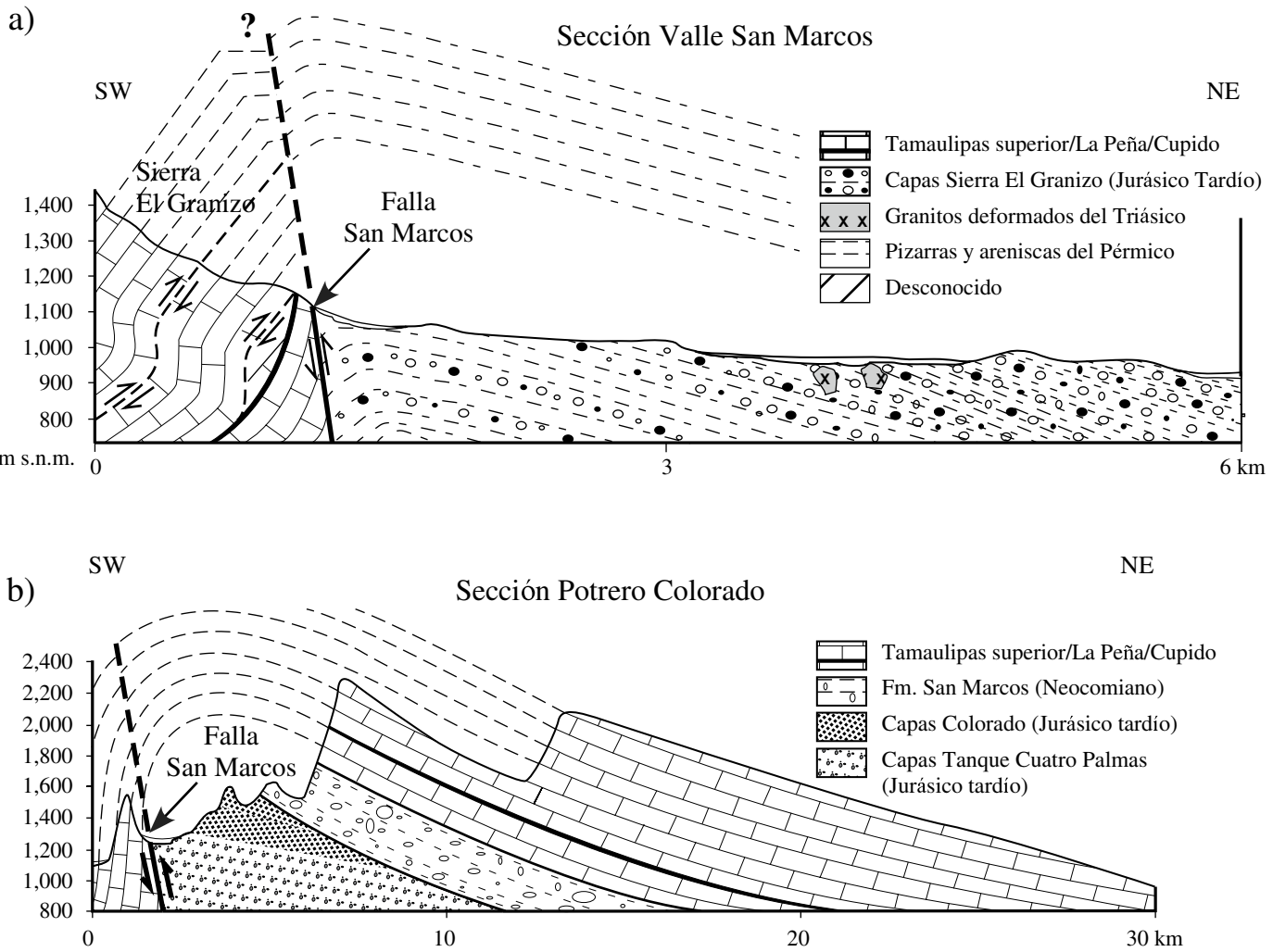

c) $\quad \mathrm{SW} \quad \mathrm{Fm}$. La Peña

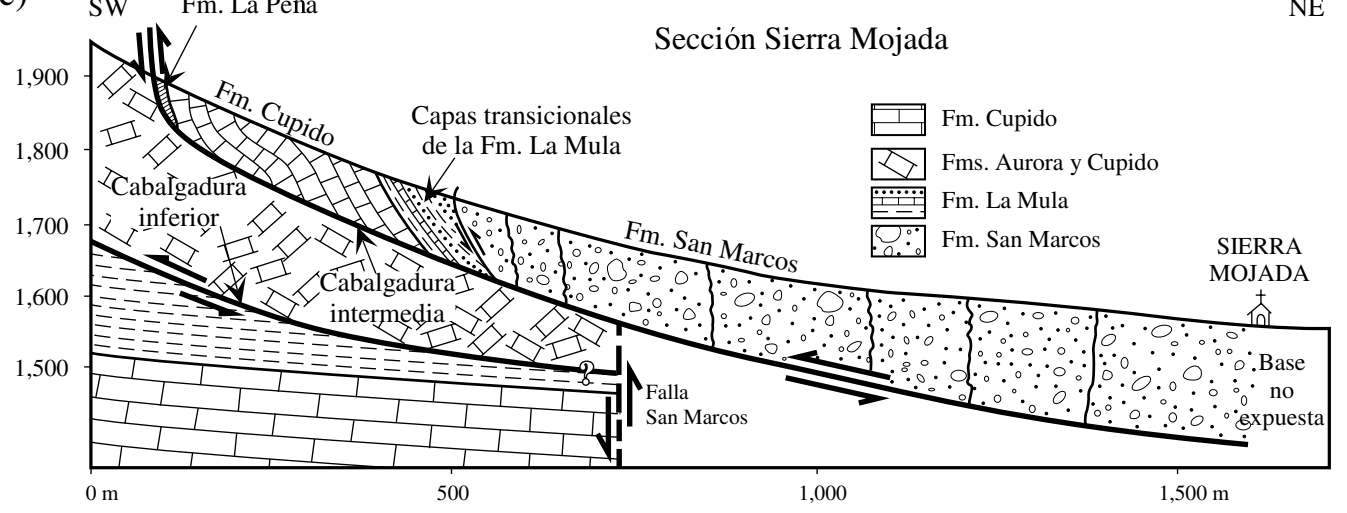

Figura 11. Secciones geológicas simplificadas que ilustran la geometría de los anticlinales asimétricos desarrollados sobre la traza de la FSM. Se interpreta que esta geometría fue controlada principalmente por la inversión tectónica del sentido de movimiento de la FSM durante la deformación laramídica. a) parte media de Valle San Marcos, localización de sección en Figura 3, b) sección del anticlinal asimétrico de la Sierra La Fragua a través de Potrero Colorado, localización de sección en Figura 6 y, c) sección geológica de Sierra Mojada (tomada de McKee et al., 1990), localización de sección en Figura 1; msnm: metros sobre el nivel del mar.

plazamientos normales y laterales menores entre el Jurásico y normales en el Cretácico Temprano. Después del relleno de las cuencas ocurrió una fase de despegues sedimentarios generándose pliegues por doblez de falla (Chávez-Cabello, 2005), los cuales precedieron a la inversión tectónica en la región que se caracterizó por la reactivación de fallas normales antiguas como fallas inversas de ángulo alto, que controlaron la generación de pliegues tipo drape con orientaciones variables que dependieron de la orientación de fallas reactivadas a la profundidad.

\subsubsection{Fallamiento Laramide en el valle de San Marcos}

La parte suroeste del VSM es la localidad donde se aprecia mayor diversidad de tipos de rocas y de edades de éstas, debido a que están yuxtapuestas a través de varias fallas de ángulo alto inclinadas hacia el noreste. Este conjunto de fallas apoyan la idea de que la FSM no es un plano de falla simple, sino que más bien corresponde a una zona de falla amplia. Las fallas de ángulo alto del VSM representan límites entre bloques tectónicos que yuxtaponen rocas más antiguas y de composición diversa progresivamente hacia 


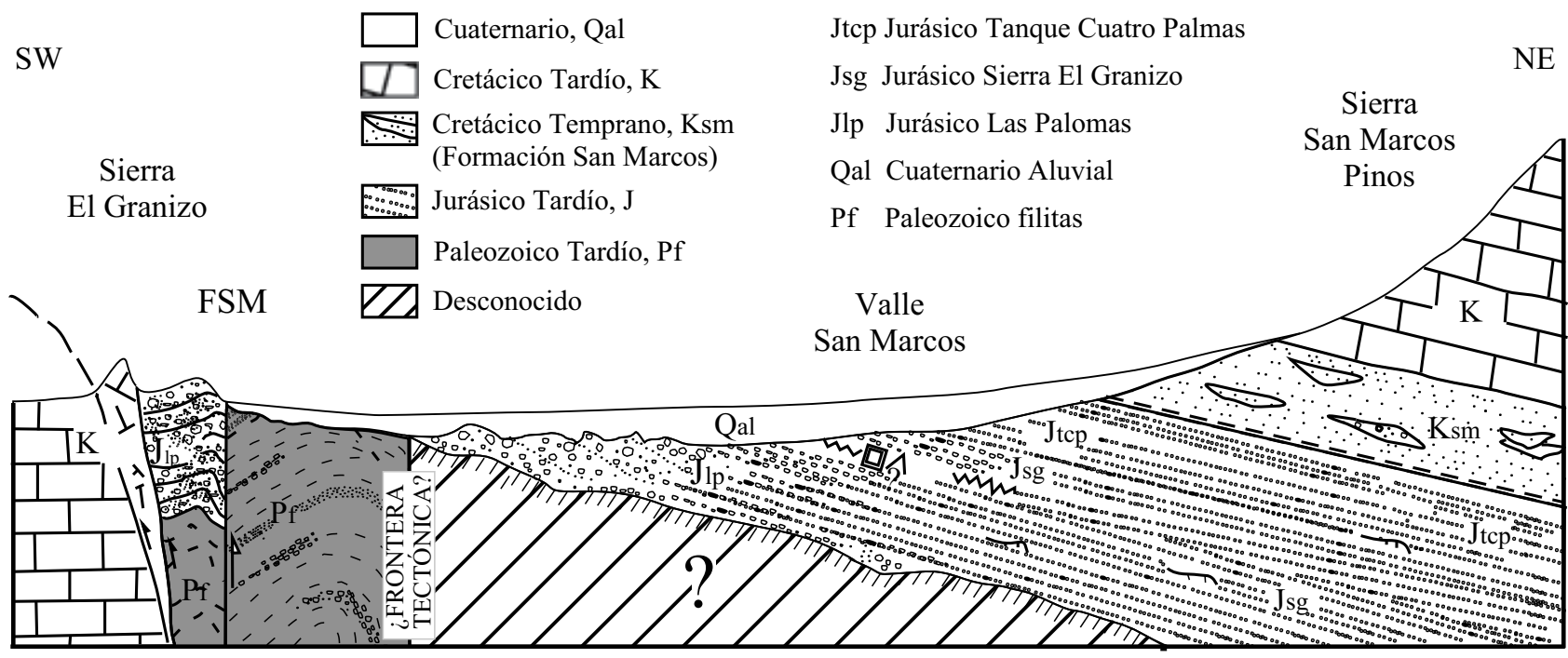

Figura 12. Sección geológica que ilustra el fallamiento vertical en el suroeste del VSM. Las rocas del Paleozoico superior son yuxtapuestas contra las del Jurásico Superior y éstas, a su vez contra las del Cretácico Tardío (modificado de McKee et al., 1990), localización de la sección en la Figura 3.

el centro del VSM (Figuras 3 y 12). La mayoría de estas fallas secundarias son de ángulo alto, lo cual es coherente con el modelo de generación de pliegues tipo drape por la inversión de fallas de basamento. En la parte suroeste del VSM existen al menos dos fallas secundarias que apoyan la idea de que el VSM fue levantado con respecto al bloque de Coahuila durante la deformación Laramide en el Paleógeno.

La falla localizada en la parte más interna del VSM (Figuras 3 y 12) pone en contacto una pizarra del Paleozoico superior con caliza de la Formación Tamaulipas Superior del Albiano, así como con rocas clásticas del Jurásico Superior (capas Las Palomas). La falla que sigue al sur hacia la Sierra El Granizo, pone en contacto a las rocas clásticas del Jurásico Superior con la caliza de la Formación Tamaulipas Superior y, finalmente, la falla más al suroeste pone en contacto a la caliza Tamaulipas Superior con sedimentos marinos clásticos de grano fino de la Formación Indidura del Cretácico Superior cerca del Cerro El Granizo (Figuras 3 y 12).

Además de las fallas anteriores, durante este trabajo se documentó una serie de fallas menores sobre la traza de la FSM, que fueron también utilizadas para definir la cinemática de su segunda reactivación mayor durante la deformación Laramide. A continuación se describen las direcciones de compresión máxima calculadas para las diferentes estaciones de fallas realizadas en el VSM.

Compresión máxima NNE a NE. Sobre la falda norte de la Sierra El Granizo se tienen tres estaciones de medición de fallas que en general definen una dirección de compresión máxima NNE a NE (SG, LP-1 y CG; Figura 13 y Tabla 1). Solamente en CG se obtuvo una dirección NE y corresponde a una estación de fallas en rocas de la Formación Indidura, aproximadamente $200 \mathrm{~m}$ al sur de la zona de doblez de la
FSM descrita anteriormente, en el área de la terminación sureste de la Sierra El Granizo (estación CG; Figura 13 y Tabla 1).

El fallamiento muestreado en la estación LP-1, al sur del ejido Las Palomas, corresponde a un sistema de fallas conjugadas inversas desarrolladas en la caliza Tamaulipas Superior (Figura 13), este fallamiento menor presenta un rumbo general paralelo a la orientación regional de la FSM. El rumbo promedio del fallamiento fue WNW-ESE, con direcciones de deslizamiento de los bloques cercanamente perpendicular al rumbo de las fallas. La orientación calculada de los esfuerzos principales para la estación LP-1, refleja fielmente el tensor esperado para un fallamiento teórico ideal en el que se considera un sistema de fallas conjugadas inversas (orientación de $\sigma_{1}$ cercanamente horizontal, $\sigma_{2}$ horizontal en el eje de intersección de los pares conjugados de fallas y $\sigma_{3}$ en posición cercanamente vertical; Figura 13; Tabla 1). Lo anterior corresponde ampliamente con la teoría expuesta en el modelo de Anderson (1951) sobre el fallamiento de bloques previamente no deformados, o en los que las superficies preexistentes tienen un efecto mínimo sobre el deslizamiento de bloques.

Una segunda estación de fallas fue realizada entre el Cerro El Granizo y la terminación sureste de la Sierra El Granizo (estación CG; Tabla 1 y Figura 13), al sur de la zona de doblez de la FSM, en lutita y arenisca calcárea de grano fino de la Formación Indidura. En este afloramiento se colectaron datos de una serie de fallas menores, a $\sim 200$ $\mathrm{m}$ al sur de la zona de falla inversa vertical más joven que sobrepone a la caliza Tamaulipas Superior sobre la lutita y arenisca de la Formación Indidura. Al igual que en la estación del ejido Las Palomas (estación LP-1), aquí también se observó un rumbo promedio del fallamiento WNW-ESE, con la presencia de pares conjugados de fallas inversas con 
direcciones de deslizamiento de los bloques perpendicular al rumbo de las fallas (pitch de $\sim 90^{\circ}$ ), pero con menor abundancia del par conjugado de fallas buzantes hacia el suroeste (estación CG, Figura 13).

Las direcciones principales de esfuerzo calculadas presentan una rotación horaria de $22^{\circ}$ con respecto a la posición obtenida en el ejido Las Palomas (estación LP-1; Figura 13 y Tabla 1), y una disminución en la inmersión de $\sigma_{1}$ y con $\sigma_{3}$ en posición más vertical en comparación con la estación LP-1 (Tabla 1). Lo anterior, es muy probable que se deba al efecto de la zona de doblez de la FSM en esta zona.

Finalmente, una tercera estación de fallas fue efectuada más al noroeste sobre la traza de la FSM, justo sobre la falda norte de la Sierra El Granizo (estación SG, Figura 13 y Tabla 1), lugar donde McKee et al. (1990) indican que aflora la FSM, debido a la yuxtaposición del conglomerado del Jurásico Superior (capas Sierra El Granizo) sobre caliza del Albiano de la Formación Tamaulipas Superior. En esta zona, se observó a la Formación La Peña (Aptiano) fuertemente cizallada separando a estratos verticales de la Formación Cupido, hacia el VSM, de estratos inclinados $\sim 45^{\circ}$ de la Formación Tamaulipas Superior.

A diferencia de las estaciones LP-1 y CG, aquí se colectaron principalmente fallas sobre la zona de cizalla vertical de la FSM y superficies de cizalla paralelas a la estratificación en el contacto Formación Cupido-La Peña. El número de fallas con orientaciones oblicuas a la estratificación colectadas en este punto ascendió a siete, y se distinguen por presentar inclinaciones suaves hacia el suroeste. El tensor de esfuerzos calculado indica una dirección de compresión máxima NNE con un $\sigma_{3}$ más vertical, influenciado por la deformación asociada con la reactivación vertical de la FSM que levantó al VSM sobre el bloque de Coahuila. En la Figura 13 se muestra el dato promedio de estratificación (círculo máximo punteado) con el fin de mostrar el paralelismo del fallamiento con ésta.

Se interpreta que el fallamiento de las estaciones LP-1 y SG, así como el fallamiento de ángulo bajo muestreado en la estación SG, corresponden a fallas generadas durante la etapa de acortamiento temprano de la deformación Laramide en la zona, caracterizado por despegues sedimentarios, mientras que el fallamiento inverso de ángulo alto de la estación SG corresponde fielmente a la deformación asociada a la inversión de la FSM en la etapa tardía de la deformación Laramide. Se destaca que en ambos casos la dirección de compresión máxima es similar (Figura 13 y Tabla 1).

Compresión máxima $W N W$. Debido al cambio claro de rumbo de WNW a casi N-S de la Sierra San Marcos Pinos (Figuras 3 y 10) y a la identificación de una variación fuerte en la inclinación de la estratificación de las capas de la Sierra La Fragua (horizontales), con respecto a las capas de la parte oeste de la Sierra San Marcos Pinos (casi verticales), se realizó una búsqueda de fallas sobre el flanco oeste del anticlinal de la Sierra de San Marcos Pinos. Sobre esta zona se hicieron dos estaciones de fallas en las que se determinó una consistencia clara en las direcciones de los ejes principales de esfuerzo, determinándose que $\sigma_{1}$ presenta una dirección prácticamente perpendicular (WNW) a la obtenida en las estaciones realizadas sobre la pared sursuroeste del VSM, en el área de la Sierra El Granizo (i.e. $\sigma_{1}$ NNE; Figura 13 y Tabla 1).

La primera estación de fallas correspondió a la SMM y la mayoría de los datos colectados fueron de fallas oblicuas a la estratificación. Las estructuras están expuestas en la entrada de una obra minera, justo en el contacto entre las formaciones San Marcos y Cupido (Figura 13 y Tabla 1). La dirección calculada del esfuerzo compresivo máximo $\sigma_{1}$ fue WNW con solamente $5^{\circ}$ de inmersión. En esta zona se presenta un plegamiento apretado, el rumbo e inclinación promedio de las capas donde se realizó la estación de fallas es de $190^{\circ} / 55^{\circ}$ (Figura 3). En esta área, donde la sierra se adelgaza, existe una zona de brecha vertical con rumbo $c a$. N-S que presenta un espesor importante de caliza de la Formación Tamaulipas Superior fuertemente triturada y cizallada, la cual se interpreta que corresponde a una zona de falla que controló el cambio de rumbo del eje de la Sierra San Marcos Pinos de WNW a ca. N-S (Figuras 3 y 10).

La segunda estación de fallas es FCW (Figura 13 y Tabla 1). Se colectaron datos de fallas inversas oblicuas a la estratificación. Las estructuras tienen rumbo N-S con inclinaciones de $30^{\circ}$ a $40^{\circ} \mathrm{W}$. La dirección calculada del esfuerzo compresivo máximo $\sigma_{1}$ fue también WNW con el mismo grado de inmersión que la estación SMM (Figura 13). Otras fallas en la Formación Tamaulipas Superior, no medidas y analizadas debido a la inaccesibilidad de la zona, fueron observadas en las partes altas del flanco oeste del anticlinal de San Marcos Pinos que indican también transporte tectónico hacia el oeste pero presentan ángulos de inclinación más verticales hacia el este y orientación N-S.

Lo trascendente al comparar los resultados de los cálculos de paleotensores de esfuerzos en las paredes del VSM, es que las direcciones del esfuerzo principal máximo son cercanamente horizontales en cuanto a inmersión pero con direcciones perpendiculares entre sí; NNE para la pared sur del VSM y WNW para la pared oeste (Figura 13 y Tabla 1). El origen de estas relaciones perpendiculares de compresión será discutido más adelante.

\subsubsection{Fallamiento Laramide en Potrero Colorado}

Compresión máxima NNE. La compresión máxima NNE a NE es la mejor representada sobre la traza de la FSM en esta zona. A la entrada del rancho Potrero Colorado, parte sur del área, se realizó una estación de fallas en la que se colectaron datos en superficies de fallas paralelas a la estratificación y oblicuas a ésta pero con ángulos de inclinación cercanos a la vertical (estación PC-12; Figura 13 y Tabla 1) muy semejantes a los de la estación SG del VSM (Figura 13). En Potrero Colorado se observa en contacto casi vertical por falla a arenisca y limolita de las capas Tanque Cuatro Palmas del Jurásico Superior con caliza y yeso del Cretácico (Figura 11b). La estación de 


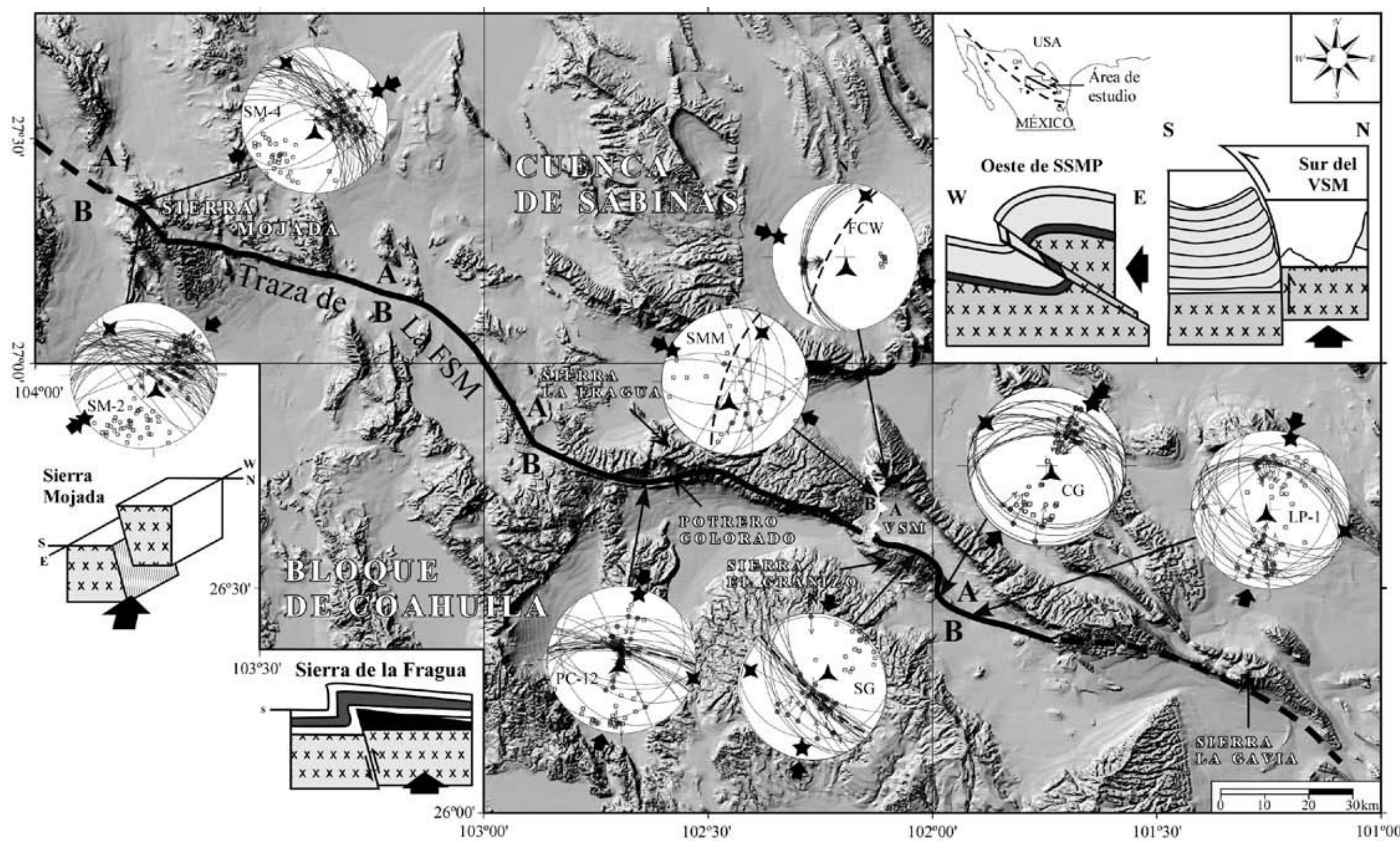

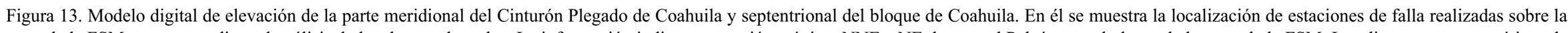
traza de la FSM en este estudio y el análisis de los datos colectados. La información indica compresión máxima NNE a NE durante el Paleógeno a lo largo de la traza de la FSM. Los diagramas esquemáticos de

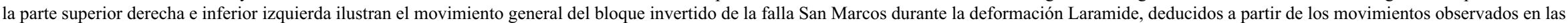
fallas, relaciones estratigráficas y por la geometría de los pliegues. VSM: Valle San Marcos. 
fallas se realizó en la entrada sur de Potrero Colorado en caliza posiblemente del Albiano, la cual está intercalada con yeso que fluyó paralelo a la estratificación durante el acortamiento. Se piensa que el yeso interestratificado con la caliza corresponde a cambios laterales de facies, justo en el borde de lapPlataforma de Coahuila, donde se sabe se depositó la Formación Acatita compuesta principalmente por yesos, de la misma edad que las formaciones Viesca (facies arrecifal) y Tamaulipas Superior (facies de cuenca) del Albiano; en el área límite entre el bloque de Coahuila y la cuenca de Sabinas, donde las condiciones lagunares favorecieron el depósito de evaporitas.

El esfuerzo compresivo máximo $\left(\sigma_{1}\right)$ tiene una inmersión de $16^{\circ}$ y está orientado N $12^{\circ}$ E (Figura 13 y Tabla 1). El esfuerzo compresivo intermedio $\left(\sigma_{2}\right)$ es horizontal y coincide con el rumbo de las fallas, mientras que $\sigma_{3}$ está en una posición cercana a la vertical. A pocos metros de donde se realizó la estación de fallas, en dirección hacia Potrero Colorado, afloran en contacto por falla inversa con ángulo muy vertical, limolita y arenisca de las capas Tanque Cuatro Palmas y la caliza intercalada con yeso del Albiano. Esta zona de falla inversa, casi vertical con inclinación hacia el norte, se interpreta aquí como la zona que representa a la superficie principal de movimiento vertical que controló la generación del pliegue tipo drape que compone a la Sierra La Fragua (Figuras 6 y 11b), y corresponde a la traza principal invertida de la FSM durante la fase tardía de la deformación Laramide en la zona.

\subsubsection{Fallamiento Laramide en Sierra Mojada}

Compresión máxima NE. La tercera y última localidad sobre la traza de la FSM en la cual se realizó un levantamiento de datos de fallas con movimientos interpretados como laramídicos es Sierra Mojada. Allí se realizaron dos estaciones de fallas (SM-2 y SM-4) sobre el cañón Palomas Negras, al noroeste de la localidad de Sierra Mojada. La dirección de compresión máxima calculada es NE y fue definida por un conjunto de fallas con rumbo WNW e inclinaciones promedio de $50^{\circ}$ (estación SM-2) y, otras con rumbo NW con inclinaciones más verticales $\left(60^{\circ}\right)$ en la estación SM-4; las fallas son principalmente inversas oblicuas (pitch promedio de $60^{\circ}$ al este; Figura 13).

Los datos de falla colectados en el cañón Palomas Negras correspondieron principalmente a fallas oblicuas que cortan a arenisca y otras rocas clásticas marinas de la Formación La Mula. La posición de los ejes principales de esfuerzo reflejan una compresión máxima oblicua a la zona de traza principal de la FSM que en esta zona es WNW. La posición de $\sigma_{1}$ es cercanamente horizontal, $\sigma_{2}$ horizontal sobre el rumbo general del fallamiento $\mathrm{y}, \sigma_{3}$ en posición cercanamente vertical (Figura 13 y Tabla 1). Sin embargo, el fallamiento inverso tiene ángulos que superan $\operatorname{los} 50^{\circ}$, por lo anterior se interpreta que la mayoría, si no es que todo el fallamiento en estas estaciones de falla, de estas fallas fueron generadas durante la reactivación inversa de la FSM en la etapa tardía de la deformación Laramide en la zona.
4.3. Tercera etapa: Fallamiento del Mioceno tardíoPlioceno temprano

El fallamiento post-Laramide presente en la región de Coahuila no es abundante y tampoco altera de manera clara el relieve como sucede en el vecino estado de Chihuahua. De acuerdo con Aranda-Gómez et al. (en prensa, a) existen al menos dos eventos de reactivación post-Laramide de la FSM en la región sureste de Chihuahua. El más antiguo ocurrió entre el Mioceno tardío y el Plioceno temprano (14 - $5 \mathrm{Ma}$ ), y es interpretado con base en que se reconocieron pliegues sinclinales suaves, con inmersión hacia el sureste y orientados NNW. Los plegamientos se presentan en rocas volcánicas con edades entre $\sim 32$ y $14 \mathrm{Ma}$, que colindan al noroeste (Sierra Aguachile) y sureste (Sierra La Herradura) con el campo volcánico de Camargo.

Las estructuras plegadas y el campo volcánico de Camargo están sobre la traza sepultada de la FSM en el sureste de Chihuahua. Estos mismos autores sugieren que la FSM puede ser extendida quizás $300 \mathrm{~km}$ más hacia el noroeste hasta cerca de Aldama, Chihuahua, en donde a $\sim 5 \mathrm{~km}$ al oeste de la sierra El Morrión hay otro sinclinal en rocas volcánicas.

De acuerdo con Aranda-Gómez et al. (en prensa, a), los plegamientos y otras alteraciones en estructuras generadas durante el evento Cuencas y Sierras sucedieron durante un lapso de compresión mínima NW, documentada en el noroeste de México y suroeste de Estados Unidos de América entre 14 y $5 \mathrm{Ma}$. Al parecer, esta fase del evento de extensión reactivó la FSM con un corrimiento normal, pero con una componente lateral pequeña. Debido a la disposición geométrica del plano de falla de basamento, respecto a esta componente lateral izquierda, se produjo acortamiento en algunas regiones, generándose estructuras aisladas que son congruentes con fallas laterales, de las cuales los sinclinales de Aguachile y La Herradura son la expresión más conspicua. Estos pliegues están orientados NNW, con inmersión hacia el SSE. Estructuras menores asociadas a los sinclinales, como fallas normales (sierras Aguachile y La Herradura) y fallas de corrimiento lateral (sintéticas y antitéticas en la Sierra La Herradura) son consistentes con esta interpretación.

Con el objeto de documentar este fallamiento en la contraparte de la FSM en el estado de Coahuila, se exploraron: a) zonas donde las estructuras Laramide pudieron haber sido afectadas por esta reactivación de la FSM, b) trazas de otras fallas de basamento sobre el bloque de Coahuila que pudieron haberse reactivado en el Mioceno tardío-Plioceno temprano y, c) cuerpos intrusivos y rocas volcánicas jóvenes emplazadas después del evento Laramide que pudieran haber registrado estos eventos de reactivación menores ocurridos sobre la FSM en el sureste de Chihuahua.

Con respecto a las estructuras Laramide en el centro de Coahuila, éstas parecen no haber sido afectadas de manera importante por las extensiones del Neógeno ya que la única localidad donde se observaron claramente zonas de brecha 
cortando a estructuras Laramide fue en el cañón El Mimbre, en la parte oriental del anticlinal de la Sierra La Fragua (Figuras 10 y 14). En esta área existe una zona amplia de brecha, con un espesor de casi 200 m (Figuras 14a y 14b), que se presenta muy cerca de la charnela del anticlinal de la Sierra La Fragua y continúa aproximadamente siguiendo su rumbo (ESE-WNW). En general, no se observan lineamientos estructurales regionales claros que desplacen a elementos estructurales laramídicos en la dirección del rumbo de la brecha, además de que esta zona amplia de brecha no continúa hacia el este donde se levanta el anticlinal de la Sierra de San Marcos Pinos.

Las estructuras dentro del área de estudio que sugieren desplazamiento sobre la traza de la FSM y a las mismas estructuras laramídicas, corresponden a dos lineamientos NNW que Eguiluz de Antuñano (1984) define como la falla Del Caballo (falla lateral izquierda) y Almagre (falla lateral derecha; Figura 1), las cuales junto con la falla Juárez conforman a tres lineamientos transcurrentes que existen al oeste de Potrero Colorado y Sierra Mojada, respectivamente (Figura 1). Consideramos que estas fallas efectivamente cortan a estructuras laramídicas generadas durante una fase temprana de la deformación, y que las fallas Del Caballo y Almagre corresponden a estructuras del basamento posiblemente reactivadas durante una fase tardía de la misma deformación Laramide. Estas fallas desplazan estructuras desde la parte occidental de la Sierra de Parras, como lo señala Eguiluz de Antuñano (1984), hasta estructuras de la parte noroeste y oeste de la cuenca de Sabinas. Especulamos que estos lineamientos pudieron ser producto de reactivaciones de fallas de basamento de la fase tardía de la deformación Laramide, semejante a lo que se observa en las inmediaciones de Cuatro Ciénegas, Coahuila (Chávez-Cabello, 2005); la edad real de actividad de estas fallas se desconoce pero como muchas otras zonas de falla en la parte central de Coahuila también canalizan magmatismo del terciario, sin haberse determinado aún si cortan o desplazan a este tipo de rocas (Figura 1).

Con respecto a la brecha mayor del cañón El Mimbre, ésta presenta en su borde desplazamientos verticales claros que cortan a estructuras Laramide previas (Figura 14c). Sin embargo, interpretamos que estos desplazamientos verticales se generaron durante el mismo evento Laramide en la región, pero en una fase de deformación más joven, en la cual ocurrió la reactivación de fallas de basamento que generaron el plegamiento tipo drape en la zona.

Con respecto a la reactivación de otras fallas de basamento sobre el bloque de Coahuila, es importante destacar que se visitó una falla que corta al basamento cerca de la localidad de Nuevo Delicias en el cañón conocido como El Agua Grande. La falla tiene un rumbo NW e inclinación hacia el suroeste y dos familias de estrías sobre el plano de falla. Las estrías más antiguas están asociadas a indicadores cinemáticos de corrimientos izquierdos definidos por escalones de falla. Las estrías más jóvenes corresponden a un desplazamiento normal que presenta el desarrollo de fibras minerales de calcita. Esta falla corta a la secuencia del Cretácico Superior en la zona por lo que se piensa que la reactivación de esta falla debe ser de edad post-Laramide (Figuras 15a y b).

Otra localidad donde se detectaron movimientos laterales menores fue en el intrusivo subvolcánico Las Tetillas del Eoceno tardío $(35.13 \pm 0.10 \mathrm{Ma}$; Chávez-Cabello, 2005), emplazado dentro del bloque de Coahuila, a $~ 15$ $\mathrm{km}$ al sur de la traza de la FSM y de la localidad conocida como Estanque Palomas. Dentro del intrusivo se observan algunos afloramientos con pares de fallas laterales, así como también una cantidad mayor de fracturas de enfriamiento que acomodaron desplazamientos laterales menores (Figuras $15 \mathrm{c}$ y $15 \mathrm{~d}$, respectivamente). Por la componente de desplazamiento observada cerca de Nuevo Delicias y en el intrusivo Las Tetillas, y más por la edad de 35.13 $\pm 0.10 \mathrm{Ma}$ del intrusivo Las Tetillas, se sugiere que este fallamiento menor pudo ser contemporáneo al evento de reactivación del Mioceno tardío-Plioceno temprano de la FSM reconocido por Aranda-Gómez et al. (en prensa, a) en el sureste de Chihuahua.

\subsection{Cuarta etapa: Fallamiento normal del Plioceno- cuaternario}

Aranda-Gómez et al. (en prensa, a) propusieron un evento de extensión del Plioceno-cuaternario en la parte sureste de Chihuahua. Este evento afectó a las rocas volcánicas máficas del campo volcánico de Camargo ( 5 - 0.09 $\mathrm{Ma}$ ), aparentemente reactivó fallas generadas en el Mioceno tardío en áreas aledañas al campo volcánico y generó fallas que cortaron a los sinclinales de Aguachile y La Herradura. A este evento de extensión NE a ENE le asignan una edad < $5 \mathrm{Ma}$. Es importante mencionar que este evento de extensión fue acompañado de un volcanismo máfico intenso en una de las inflexiones de la FSM que en este lapso actuó al parecer como una estructura tipo pull-apart.

En Coahuila, el volcanismo máfico está presente en varias localidades dentro de la cuenca de Sabinas como en el campo volcánico Las Esperanzas y el campo volcánico de Ocampo (Valdez-Moreno, 2001); y una más sobre el bloque de Coahuila conocida como el campo volcánico Las Coloradas (Figura 1). Sin embargo, este volcanismo prácticamente no está acompañado de fallamiento normal como el que describieron Aranda-Gómez et al. (2003) para el campo volcánico de Camargo. Lo que se observa en los campos volcánicos de Coahuila es que el magmatismo fue canalizado a través de discontinuidades del basamento antiguas como las fallas La Babia, San Marcos y los bordes de la isla de La Mula, este último en la parte central de la cuenca de Sabinas (Aranda-Gómez et al., en prensa, b).

Es importante señalar que existen algunas fallas normales orientadas en general NW-SE con desplazamiento vertical menor en las inmediaciones del bloque de Coahuila y en la cuenca de Sabinas (Figura 10). Además, existe un 


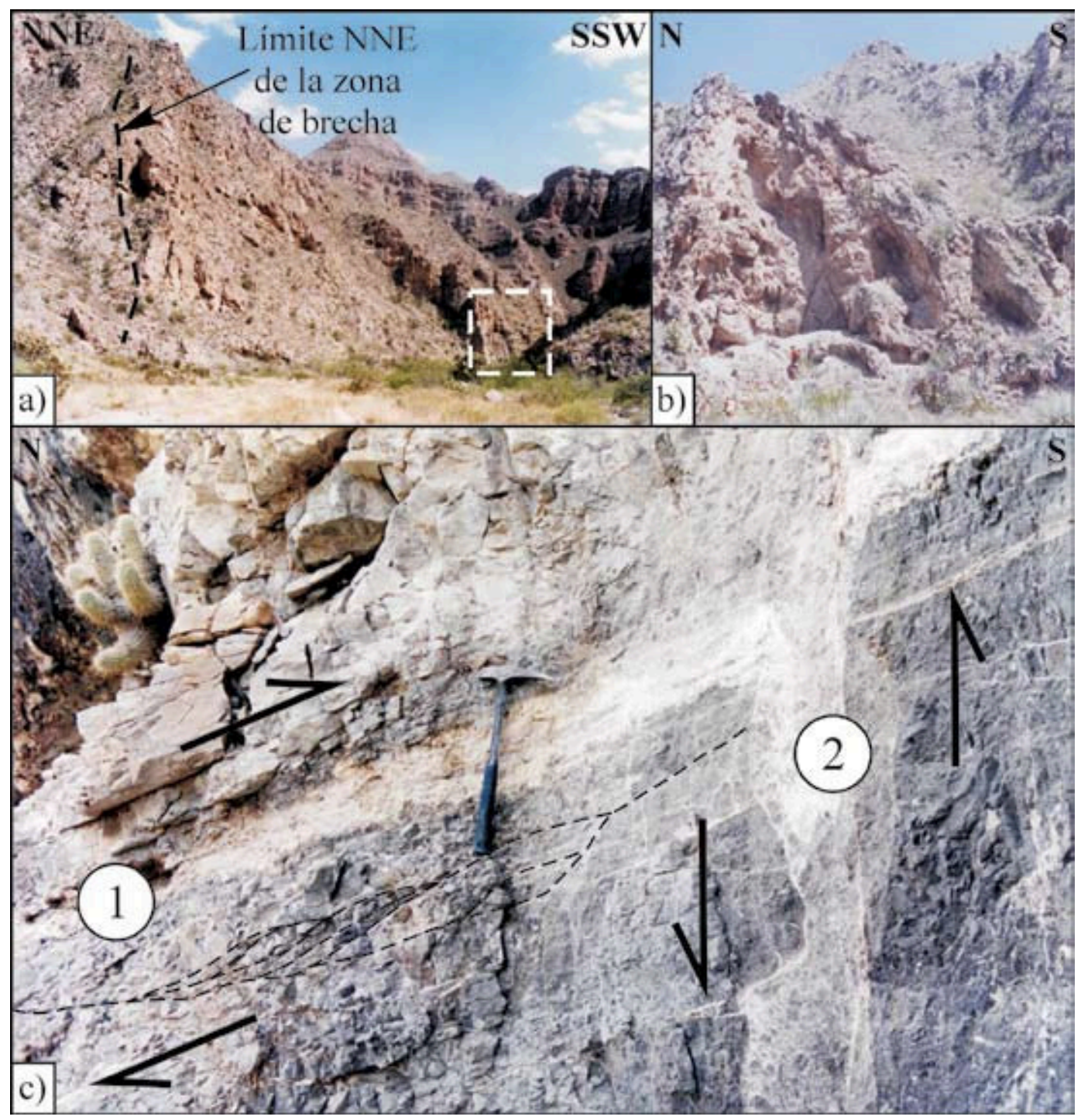

Figura 14. a) Zona de brecha vertical dentro de la caliza de la Formación Viesca con un espesor de casi $200 \mathrm{~m}$, el recuadro inferior derecho corresponde al acercamiento presentado en "b", b) Acercamiento de la zona de deformación y, c) Superficies de cizalla paralela a la estratificación (1) que son cortadas y desplazadas por zonas de brecha vertical (2) en el borde SSW de la brecha mayor. Se interpreta que estas estructuras representan a estructuras menores relacionadas con la primera (1) y segunda (2) fase de deformación en la cuenca de Sabinas.

alineamiento de centros magmáticos que sugieren la existencia de algún accidente estructural paralelo y al sur de la FSM. El alineamiento magmático que aquí se propone lo formarían el cuello volcánico La Víbora (ubicado entre las sierras Los Alamitos y El Granizo), el intrusivo Las Tetillas (al este de la Sierra Los Alamitos) y el campo volcánico Las Coloradas (entre las sierras Los Alamitos, La Paila y San Marcos Pinos). Solamente en el cuello volcánico La Víbora existen evidencias que sugieren la existencia de una falla normal relacionada con el magmatismo (Figura 10), donde el bloque al sur es el bloque de techo de la falla, cayendo en la misma dirección.

Por otro lado, en el cañón el Agua Grande, cerca de Nuevo Delicias, se documentaron superficies estriadas con indicadores cinemáticos congruentes con desplazamientos normales. Este movimiento normal ocurrió sobre una falla preexistente que corta al basamento sobre la que ocurrió extensión en dirección NNE (Figura 15b). Otra de las localidades donde también fue documentado fallamiento normal con desplazamientos menores corresponde al intrusivo Las Tetillas. Allí los acomodamientos normales entre bloques ocurren a lo largo de fracturas de enfriamiento $\mathrm{y}$, en algunas ocasiones, estos acomodamientos normales ocurren sobre superficies preexistentes de fallas laterales más antiguas (Figuras 15e y f). Finalmente, en el borde de la parte norte del anticlinal de la Sierra La Fragua y Sierra Los Alamitos hay desplazamientos normales menores con orientaciones NW-SE que sugieren extensión NE-SW (Figura 10). En este trabajo se sugiere que estos eventos de fallamiento post-Eoceno tardío, lateral y normal, pueden corresponder 
a los reconocidos en el campo volcánico de Camargo por Aranda-Gómez et al. (en prensa, a) para el Mioceno tardíoPlioceno temprano y Plio-cuaternario, respectivamente.

\section{Discusión}

\subsection{Acerca del origen de la Falla San Marcos}

McKee et al. (1984) concluyen que, aunque no se pueden probar o excluirse desplazamientos laterales grandes sobre la FSM, si se puede sugerir que debido a su tamaño, orientación, localización y cronología de los movimientos sobre ésta, pudo ser parte de la falla Mojave-Sonora postulada por Anderson y Schmidt (1983) o una ramificación de esa estructura. Posteriormente, estos mismos autores sugirieron que la FSM pudo haber formado parte de un sistema de fallas transformantes que conectaron dorsales oceánicas entre el Atlántico y el Pacífico, las cuales acomodaron desplazamientos laterales izquierdos en el Jurásico Tardío (McKee et al. 1990). Independientemente del escenario, de acuerdo con estos modelos propuestos, la FSM debió implicar grandes desplazamientos laterales. Sin embargo, grandes desplazamientos sobre la traza de la FSM aún no han sido probados. Más aún, hoy en día continua un fuerte debate sobre la existencia y el origen de la falla MojaveSonora (e.g. Molina-Garza y Geissman, 1996, 1999; Iriondo, 2001), que en primer instancia implica mucho mayores desplazamientos laterales que los que pudieron haber ocurrido sobre la FSM.

Por otro lado, se han propuesto tres modelos tectónicos sobre el origen de la cuenca de Sabinas. Este rasgo paleogeográfico ha sido interpretado como: 1) cuenca pull-apart (Longoria, 1984; Santamaría et al., 1991), 2) cuenca intracratónica (aulacógeno o rift abortado; Charleston, 1973; Alfonso, 1978) y 3) cuenca intracontinental producto de un proto-rift (Salvador, 1991; Eguiluz de Antuñano, 2001). En cada uno de los modelos la FSM actuaría como la falla maestra al sur de la cuenca. El primer modelo implicaría que la FSM se instauró como una falla de desplazamiento lateral, para el segundo y tercer modelo funcionaría más como una falla normal.

Las evidencias estructurales recabadas durante la presente investigación indican que hay la posibilidad de que la FSM haya sido originada como una falla de desplazamiento lateral. Sin embargo, aún cuando se determinaron rotaciones importantes en rocas del Jurásico Superior en el VSM (Molina-Garza et al., 2003; Arvizu-Gutiérrez, 2003), el tiempo de estas rotaciones puede no necesariamente ser del Jurásico Tardío, sino haberse originado durante la deformación Laramide del Paleógeno, que ocurrió en dos fases dentro de la cuenca de Sabinas (Chávez-Cabello, 2005). Estos modelos aún tienen que ser explorados con mayor detalle con estudios paleomagnéticos-estructurales más completos en el VSM y Potrero Colorado. Lo que es claro en Potrero Colorado es que el fallamiento dominante, y que muestra desplazamientos mayores (hasta decenas de metros), es el de tipo normal y ha sido retomado para acomodar desplazamientos laterales derechos menores $(<1 \mathrm{~m})$ en el mismo Jurásico Tardío.

Otra característica del fallamiento en las rocas jurásicas, es que fue acompañado por una sedimentación sintectónica intensa, especialmente en las capas Tanque Cuatro Palmas de Potrero Colorado. El conglomerado identificado por McKee et al. (1990) entre esta unidad y las capas Colorado (Figura 2), debe reflejar un rejuvenecimiento menor del relieve en la zona o un abatimiento del nivel marino.

En general, las fallas documentadas en las capas Tanque Cuatro Palmas y Colorado (eolianita) en Potrero Colorado, indican que ocurrió más extensión en la parte central de Coahuila que desplazamientos laterales desde el Jurásico Tardío hasta el Neocomiano. Bajo este criterio, podemos pensar que la cuenca de Sabinas pudo haberse generado más como una cuenca asociada con pulsos de extensión franca NNE-SSW, delimitada por la FSM en el suroeste, que como una cuenca pull-apart en zonas de desplazamiento lateral mayor. Aunque, por ahora, quedará la duda si Potrero Colorado corresponde a la zona de mayor extensión dentro de una cuenca tipo pull-apart. Una inferencia puede ser hecha con base en que las fallas San Marcos y La Babia, que delimitan a la cuenca de Sabinas, tienen rumbos paralelos y no parecen unirse en ninguno de los extremos de la cuenca de Sabinas. Lo anterior estaría en contra, a escala regional, de que la cuenca de Sabinas sea una cuenca ideal tipo pull-apart.

\subsection{Sobre las reactivaciones de la falla San Marcos}

McKee et al. (1990) sugirieron que el primer evento de reactivación de la FSM sucedió en el Cretácico Temprano y fue originado por ajustes isostáticos. Esta interpretación se apoya en la ocurrencia de una cuña de sedimentos clásticos con $1000 \mathrm{~m}$ de espesor que compone a la Formación San Marcos y que marcan el cambio de ambiente marino (capas Tanque Cuatro Palmas) a continental (Formación San Marcos) en la parte central de Coahuila. Las evidencias estructurales que documentan este primer evento de reactivación fueron identificadas en este trabajo. Como se mostró anteriormente, el fallamiento normal observado en el contacto entre las capas Colorado y la Formación San Marcos, que aquí se sugiere, documenta este período de reactivación, las fallas presentan saltos verticales mucho mayores que los observados en las capas del Jurásico Tardío en Potrero Colorado.

Parece ser que el fallamiento del Cretácico Temprano controló ampliamente el rejuvenecimiento del relieve en la zona. El fallamiento aquí presentado muestra claramente que extensión mayor NNE ocurrió para este tiempo. Es importante resaltar que no existen diferencias importantes entre la inclinación y orientación de las fallas del Jurásico Tardío y las del Neocomiano. Sin embargo, el primer 
a)

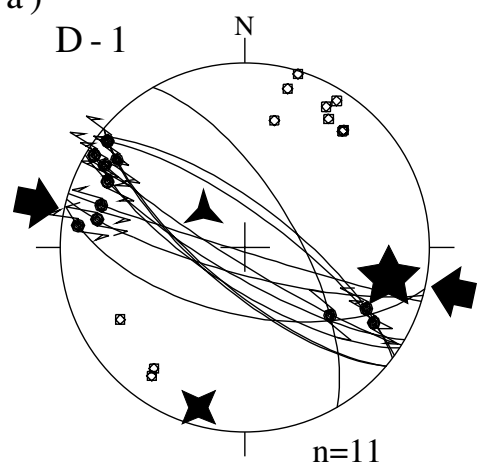

d)

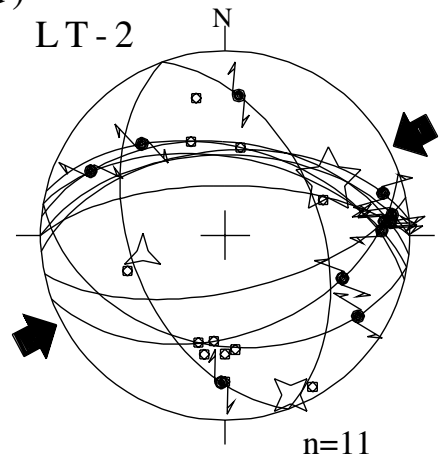

b)

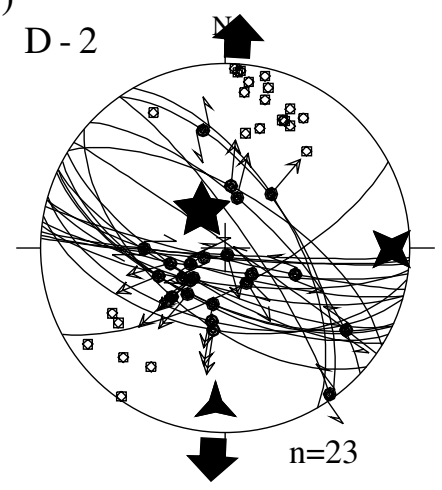

e)

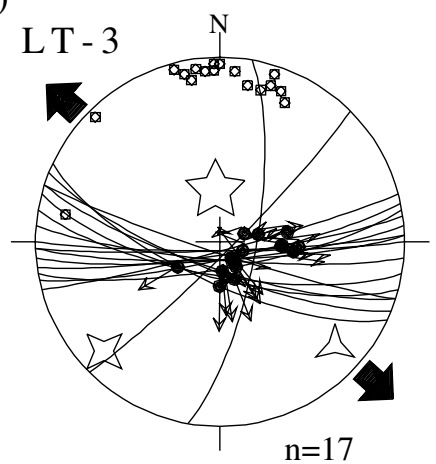

c)

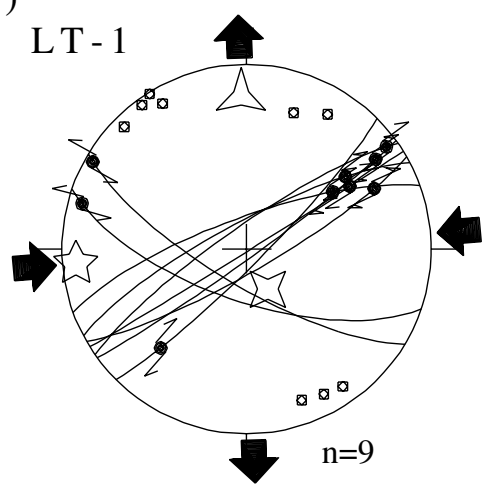

f)

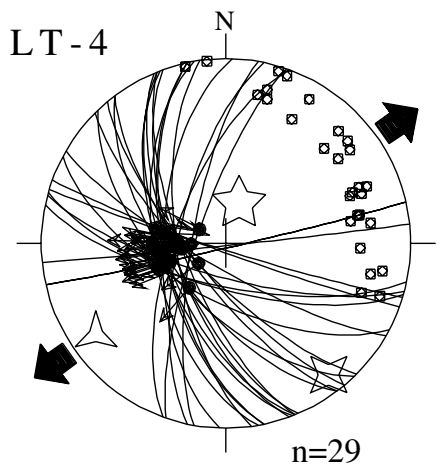

Figura 15. a) y b) Redes estereográficas que muestran la interpretación de datos de falla colectados en el área de Nuevo Delicias, ver Figura 10 para ubicar localidad. a) Fallas laterales en granitos del basamento del bloque de Coahuila; b) fallas normales en la secuencia del Cretácico Superior; nótese que las estructuras en a) y b) son paralelas a los alineamientos que son interpretados como productos de fallas regionales WNW de basamento, c), d), e) y f) son del intrusivo Tetillas, ver Figura 10 para ubicar localidad; c) fallas conjugadas con desplazamiento lateral medidas dentro del intrusivo Las Tetillas del Eoceno tardío; d) fracturas de enfriamiento que acomodaron movimientos laterales; e) fallas normales con estrías ligeramente oblicuas hacia el este, consistentes con compresión mínima NW; f) fallas normales con pitch cercano a $90^{\circ}$ y rumbos altamente variables que definen una dirección de compresión mínima NE, la variabilidad en el rumbo de las estructuras es atribuida a que el fallamiento normal retomó planos preexistentes. Éste es un ejemplo donde falla el programa INVD de Angelier (1990) para el cálculo del tensor de esfuerzos, debido a que los bloques interactúan entre ellos para acomodar la extensión (Nieto-Samaniego y Alaniz-Álvarez, 1997). Los diagramas c), d) y f) fueron tomados de García-Quintero (2004).

periodo de reactivación se interpreta porque existe un cambio drástico en el ambiente de depósito de marino a continental, justificado por la existencia de las capas marinas Tanque Cuatro Palmas con fósiles del Titoniano sobre las cuales se depositó la Formación San Marcos de ambiente continental. Además, en este trabajo se reconoció que el fallamiento lateral derecho antiguo, presente en las rocas jurásicas, no ocurre durante la reactivación del Neocomiano, el cual es de tipo normal. Es importante señalar que entre el Jurásico Tardío y el Neocomiano ocurrieron principalmente pulsos de extensión intermitentes que contribuyeron ampliamente en el desarrollo de la cuenca de Sabinas. Sin embargo, no se debe subestimar la reactivación lateral derecha menor de las fallas normales más antiguas presentes en las capas Colorado (Figura 5a), ya que podrían implicar desplazamientos laterales importantes que aún no pueden ser estimados.

Con respecto al evento de reactivación de la FSM en el
Paleógeno, es claro que existió una inversión del sentido de la componente original de movimiento hacia el echado en la FSM. En este trabajo se documentaron fallas inversas NW-SE a WNW-ESE a lo largo de la traza de la FSM, especialmente sobre las partes frontales de los pliegues tipo drape causados por la inversión de la FSM. Las direcciones de compresión máxima calculadas utilizando fallas son muy consistentes de NNE a NE desde Sierra Mojada hasta el VSM a lo largo de la traza de la FSM. Adicionalmente, la yuxtaposición de rocas más antiguas hacia el NE a través de fallas inversas de ángulo alto en el VSM (McKee et al., 1990) y Potrero Colorado (Chávez-Cabello, 2005) apoyan fuertemente esta hipótesis.

Las direcciones perpendiculares de ejes de pliegues mayores en el suroeste de la cuenca de Sabinas, junto con el cambio de rumbo de NW-SE a N-S de la Sierra de San Marcos Pinos (Figura 10), y las direcciones perpendiculares de transporte tectónico entre la pared suroeste 
y oeste del VSM (Figura 13), sugieren la reactivación de fallas secundarias oblicuas a la traza de la FSM durante el evento de deformación Laramide. Las fallas de basamento secundarias que controlaron a estos cambios de orientación de estructuras y de transporte tectónico quizás fueron generadas durante el ajuste isostático propuesto por McKee et al. (1990) para el Cretácico Temprano o hasta en el mismo Jurásico Tardío, debido a que existe un cambio claro de las facies sedimentarias entre VSM y Potrero Colorado para este tiempo (McKee et al., 1990).

La inversión de fallas secundarias de basamento explican las orientaciones de ejes de pliegue casi perpendiculares entre sí, aunque la dirección de acortamiento regional no cambió entre lo que parecen ser dos fases de la deformación Laramide en la zona (Chávez-Cabello, 2005).

La reactivación de la FSM del Mioceno tardío-Plioceno temprano propuesta por Aranda-Gómez et al. (en prensa, a) en el sureste de Chihuahua, que acomodó desplazamiento lateral izquierdo menor durante un periodo de extensión corto en dirección NW-SE, se manifiesta sutilmente sobre la traza de la FSM en Coahuila, ya que durante este trabajo se reconocieron algunos planos de falla, dentro de la zona de brecha vertical mayor en el cañón El Mimbre, con indicadores cinemáticos izquierdos; sin embargo, estas fallas no acomodaron desplazamientos importantes. Por otro lado, las fallas laterales observadas en el intrusivo Las Tetillas del Eoceno tardío (García-Quintero, 2004), así como la reactivación de la falla de basamento cerca de Nuevo Delicias, sugieren que reactivaciones menores también ocurrieron al sur de la traza de la FSM.

El fallamiento normal del Plioceno tardío - cuaternario, reconocido por Aranda-Gómez et al. (en prensa, a) sobre la traza sepultada de la FSM en el sureste de Chihuahua, parece no manifestarse claramente sobre la traza de la FSM en el centro de Coahuila. Sin embargo, en la zona que está aproximadamente $15 \mathrm{~km}$ al sur de la traza de la FSM, existe un alineamiento de centros magmáticos paralelos a ésta. En uno de estos centros volcánicos al parecer coexistieron magmatismo y fallamiento normal (Cerro La Víbora). Esto es similar a la actividad descrita por Aranda-Gómez et al. (2003) en el campo volcánico de Camargo. Además, hay desplazamientos normales pequeños también identificados en el intrusivo las Tetillas (Figura 10) y en la falla de basamento localizada cerca de Nuevo Delicias. Lo anterior, sugiere que la actividad tectónica-magmática post-Laramide en la parte central de Coahuila parece haber migrado de la posición de la traza de la FSM hacia el sur, a diferencia de lo que ocurrió en Chihuahua. Otra alternativa sobre la poca manifestación del fallamiento normal Neógeno en la zona es que las evaporitas en la región del CPC continúen inhibiendo la formación de fallas normales en el área, aun y cuando el área está bajo un régimen extensivo (Suter, 1991); lo anterior, quizás se deba a que la deformación es absorbida casi totalmente por el horizonte evaporítico (Formación Olvido), comportándose éste dúctilmente en lugar de frágil.
No cabe duda que en la parte central de Coahuila las estructuras de basamento como la FSM y fallas secundarias asociadas a ésta controlaron la orientación e inclinación de las estructuras generadas a partir del Jurásico Tardío - Cretácico Temprano. En la región muchos de los ejes de pliegues y trazas de falla tienen orientaciones WNW a NW, similar al rumbo inferido de las trazas de la FSM y de la falla de basamento al sur de Nuevo Delicias. Este hecho causa que el estudio de los eventos de reactivación en zonas en donde existen discontinuidades mayores en el basamento sea complicado porque los eventos tectónicos más jóvenes sobreponen sus características sobre estructuras más antiguas. Por lo tanto, el análisis de la evolución tectónica de la región requiere de un estudio detallado no sólo de las estructuras y de las relaciones de corte entre ellas, sino de los patrones de sedimentación, distribución de facies y cambios espaciales en el espesor de las unidades litoestratigráficas así como de sus edades. Por otro lado, la geometría original de la FSM y otros rasgos de basamento sepultados bajo centenas o miles de metros de sedimentos, son difíciles de discernir con precisión y, en aquellos estudios basados sólo en el análisis de rasgos expuestos en la superficie, siempre existirá la duda de si esta geometría original fue preservada o si se modificó gradualmente en etapas de deformación posteriores.

Los datos aportados en este trabajo sobre las reactivaciones de la FSM, la cual delimita en la parte sur a la cuenca de Sabinas, son limitados y no permiten resolver cuál de las hipótesis planteadas es la mejor acerca del origen de la cuenca de Sabinas, ya que corresponden solamente a la parte sur. Sin embargo, esta información realza la importancia de las fallas con desplazamientos principalmente normales del Jurásico Tardío - Cretácico Temprano en la génesis de la cuenca.

Se puede destacar que la orogenia Laramide es el evento mejor representado en las estructuras de la región, por la abundancia de fallas y pliegues con ese origen en todas las localidades visitadas. También hay evidencias estratigráficas y sedimentológicas acerca de la actividad temprana de la FSM preservadas en las rocas clásticas del Jurásico Superior (capas Las Palomas, Sierra El Granizo y Tanque Cuatro Palmas) y del Cretácico Inferior (Formación San Marcos). Sobre las direcciones de acortamiento y extensión posteriores al evento Laramide debe de trabajarse aún con mayor detalle para definir los mecanismos involucrados y valorar la importancia de estas reactivaciones en la parte central de Coahuila o explicar su ausencia en el área.

Finalmente, un aspecto importante que debe ser explorado en detalle es el análisis de la evolución del plegamiento laramídico en la parte sur de la cuenca de Sabinas, ya que hay evidencias que sugieren que existieron dos fases de deformación. Lo anterior es de importancia medular desde el punto de vista económico debido a que en la zona existen yacimientos de hidrocarburos, de minerales metálicos y acuíferos profundos los cuales pueden ser mejor aprovechados para un mejor desarrollo económico de la región. 


\section{Conclusiones}

La FSM es la estructura de basamento mejor documentada en el noreste de México. Esta estructura es la que mejor muestra en superficie evidencias estratigráficas $\mathrm{y}$ estructurales que documentan su actividad intermitente desde el Jurásico Tardío al Plioceno-cuaternario. Los rasgos estructurales y estratigráficos reconocidos indican que entre el Jurásico Tardío y el Neocomiano esta falla acomodó principalmente extensión de la corteza en dirección NNE, que debió contribuir al crecimiento de la cuenca de Sabinas; con lo anterior, se pone en duda la existencia de grandes desplazamientos laterales (de decenas de kilómetros) a través de ésta.

Por otro lado, la reactivación con componente inversa de la FSM en el Paleógeno generó plegamiento tipo drape en la zona entre el VSM y la Sierra Mojada. Esta reactivación parece ser posterior a una fase inicial donde la deformación fue dominada por despegues sedimentarios con transporte tectónico hacia el NNE en la plataforma de Coahuila y sur de la cuenca de Sabinas. Esta hipótesis debe ser explorada con mayor detalle en trabajos futuros. Las relaciones perpendiculares entre ejes de pliegues en la parte suroeste de la cuenca de Sabinas, el levantamiento de rocas más antiguas progresivamente hacia el noreste dentro del VSM y las relaciones perpendiculares de acortamiento tectónico determinadas en el mismo VSM sugieren que además de la FSM, debieron reactivarse otras fallas de basamento secundarias a la FSM durante la deformación Laramide del Paleógeno.

Finalmente, la reactivación lateral izquierda del Mioceno tardío-Plioceno del sureste de Chihuahua sobre la FSM, al igual que la reactivación normal del Plioceno-cuaternario, no son muy evidentes sobre la traza de la FSM en Coahuila, aunque acomodamientos de este tipo fueron reconocidos sobre el bloque de Coahuila al sur de la FSM y algo de fallamiento normal sobre el flanco norte de la Sierra La Fragua y Los Alamitos. Más trabajo estructural y paleomagnético debe ser realizado para determinar si las rotaciones paleomagnéticas en las rocas clásticas del Jurásico Superior, documentadas recientemente en el VSM, ocurrieron en el Jurásico o son producto de la deformación laramídica compleja del Paleógeno.

\section{Agradecimientos}

Este trabajo forma parte de la disertación doctoral del primer autor, quien agradece a la UANL (PROMEP) por el apoyo brindado durante sus estudios. El financiamiento para realizar trabajo de campo y estudios de laboratorio se obtuvo principalmente del proyecto Conacyt 37429-T a R. Molina, G. Chávez y J. Aranda. G. Chávez también recibió apoyo económico por parte de PAEP como estudiante del Posgrado en Ciencias de la Tierra de la UNAM. ArvizuGutiérrez gozó de una beca-tesis del Conacyt a través del proyecto 37429-T. Agradecemos a Samuel Eguiluz sus comentarios sobre la primer versión de este trabajo y a los revisores Ángel F. Nieto Samaniego y Randall Marrett, por sus valiosos comentarios que permitieron mejorar ampliamente el presente trabajo.

\section{Referencias bibliográficas}

Alfonso, Z. J., 1978, Geología regional del sistema sedimentario Cupido: Boletín de la Asociación Mexicana de Geólogos Petroleros, 30 (1, 2), 1-55.

Anderson, E.M., 1951, The dynamics of faulting, 2nd edition: Edinburgh, Oliver \& Boyd, $206 \mathrm{p}$.

Anderson, T. H., Schmidt, V. A., 1983, The evolution of middle America and the Gulf of Mexico-Caribbean Sea region during Mesozoic time: Geological Society of America Bulletin, 94, 941-966.

Angelier, J., 1990, Inversion of field data in fault tectonics to obtain the regional stress. III. A new rapid direct inversion method by analytical means: Geophysical Journal International, 103, 363-376.

Aranda-Gómez, J.J., Housh, T.B., Luhr, J.F., Henry, C.D., Becker, T., Chávez-Cabello, G., en prensa, a, Reactivation of the San Marcos fault during mid- to late- Tertiary extension, Chihuahua, Mexico: Geological Society of America, Special Paper.

Aranda-Gómez, J.J., Luhr, J.F., Housh, T.B., Valdez-Moreno, G., ChávezCabello, G., en prensa, b, El vulcanismo intraplaca del Cenozoico Tardío en el centro y norte de México: una revisión, en NietoSamaniego, A.F. y Alaniz-Alvarez, S.A. (eds.), Temas selectos de la Geología Mexicana: Boletín de la Sociedad Geológica Mexicana, 57 (3).

Aranda-Gómez, J.J., Luhr, J.F., Housh, T.B., Connor, C.B., Becker, T., Henry, C.D., 2003, Synextensional Plio-Pleistocene eruptive activity in the Camargo volcanic field, Chihuahua, México: Geological Society of America Bulletin, 115 (3), 298-313.

Arvizu-Gutiérrez, I.R., 2003, Estudio paleomagnético de los granitoides permo-triásicos y de las capas Las Palomas (Jurásico Tardío), Valle San Marcos, Coahuila, México: Linares, Nuevo León, Universidad Autónoma de Nuevo León, Facultad de Ciencias de la Tierra, Tesis profesional, $116 \mathrm{p}$.

Buchanan, P.G., McClay, K.R., 1991, Sandbox experiments of inverted listric and planar faults systems, en Cobbold, P.R., (ed.), Experimental and numerical modelling of continental deformation: Tectonophysics, 188, 97-115.

Charleston, S., 1973, Stratigraphy, tectonics and hydrocarbon potential of the lower Cretaceous, Coahuila series, Coahuila, Mexico: Michigan, University of Michigan, Tesis doctoral, $268 \mathrm{p}$.

Charleston, S., 1981, A summary of the structural geology and tectonics of the state of Coahuila, Mexico, en Schmidt, C. I., Katz, S. B., (eds.), Lower Cretaceous stratigraphy and structure, northern Mexico: West Texas Geological Society, Field Trip Guidebook, Publication, 81-74, 28-36.

Chávez-Cabello, G., 2005, Deformación y magmatismo Cenozoico en el sur de la Cuenca de Sabinas, Coahuila, México: Juriquilla, Querétaro, Universidad Nacional Autónoma de México, Centro de Geociencias, Tesis doctoral, $226 \mathrm{p}$.

Eguiluz de Antuñano, S., 1984, Tectónica cenozoica del norte de México: Boletín de la Asociación Mexicana de Geólogos Petroleros, 36 (1), 43-62.

Eguiluz de Antuñano, S., 2001, Geologic evolution and gas resources of the Sabinas basin in northeastern Mexico, en Bartolini, C., Buffler, R.T., Cantú-Chapa, A., (eds.), The western Gulf of Mexico Basin: tectonics, sedimentary basins, and petroleum systems: Tulsa, Oklahoma, American Association of Petroleum Geologist, Memoir, 75, 241-270.

García-Quintero, J.J., 2004, Cartografía y análisis estructural del intrusivo Las Tetillas, Coahuila, México: Linares, Nuevo León, Universidad Autónoma de Nuevo León, Facultad de Ciencias de la Tierra, Tesis profesional, $101 \mathrm{p}$. 
Goldhammer, R.K., 1999,: Mesozoic sequence stratigraphy and paleogeographic evolution of northeast of Mexico, en Bartolini, C., Wilson, J.L., Lawton, T.F., (eds.), Mesozoic sedimentary and tectonic history of north-central Mexico: Boulder, Colorado, Geological Society of America, Special Paper, 340, 1-58.

Harding, T.P., 1985, Seismic characteristics and identification of negative flower structures, positive flower structures, and positive structural inversion: Bulletin of the American Association of Petroleum Geologists, 69, 582-600.

Iriondo, A., 2001, Proterozoic basaments and their Laramide juxtaposition in NW Sonora, Mexico: Boulder, Colorado, University of Colorado, Tesis doctoral, $222 \mathrm{p}$.

Jones, N.W., Dula, F., Long, L.E., McKee, J.W., 1982, An exposure of A fundamental fault in Permian basement granitoids, VSM, Coahuila, México: Geological Society of America, Abstract with Programs, $14,523-524$.

Longoria, J.F., 1984, Stratigraphic studies in the Jurasic of northeastern Mexico: evidence of the origin of the Sabinas Basin, en Ventres, W. P. S., Bebout, D. G., Perkins, B. F., Moore, C. H., (eds.), The Jurassic of the gulf rim. Proceedings of the Third Annual Research Conference: Austin, Texas, Society of Economic Paleontologists and Mineralogists Foundation, Gulf Coast Section, 171-193.

McKee, J. W., Jones, N. W., Long, L. E., 1984, History of recurrent activity along a major fault in northeastern Mexico: Geology, 12, 103-107.

McKee, J. W., Jones, N. W., Anderson, T. H., 1988, Las Delicias Basin: a record of late Paleozoic arc volcanism in northeastern Mexico: Geology, 16, 37-40.

McKee, J. W., Jones, N. W., Long, L. E., 1990, Stratigraphy and provenance of strata along the San Marcos fault, central Coahuila, Mexico: Geological Society of America Bulletin, 102, 593-614.

McKee, J. W., Jones, N. W., Anderson, T. H., 1999, Late Paleozoic and early Mesozoic history of the Las Delicias terrane, Coahuila, México, en Bartolini, C., Wilson, J.L., Lawton, T.F., (eds.), Mesozoic sedimentary and tectonic history of north-central Mexico: Boulder, Colorado, Geological Society of America, Special Paper, 340, 161-189.

Molina-Garza, R.S., 2005, Paleomagnetism and geochronology of the Late Triassic Acatita intrusives, Coahuila, Mexico, Geofísica Inernacional, 44, 197-210.

Molina-Garza, R.S., Geissman, J.W., 1996, Timing of deformation and accretion of the Antimonio terrane, Sonora, from paleomagnetic data: Geology, 24, 1131-1134.
Molina-Garza, R.S., Geissman, J.W., 1999, Paleomagnetic data from the Caborca terrane, Mexico: implications for Cordillera tectonics and the Mojave-Sonora megashear: Tectonics, 18, 293-325.

Molina-Garza, R.S., Arvizu-Gutiérrez, I.R., Chávez-Cabello, G., 2003, Paleomagnetismo de la Fm. Palomas (Jurásico) y granitoides permo-triásicos, sur de Coahuila: implicaciones Tectónicas: GEOS, 23 (2), 112.

Nieto-Samaniego, A. F., Alaniz-Alvarez, S. A, 1997, Origin and tectonic interpretation of multiple fault patterns: Tectonophysics, 270, 197-206.

Padilla y Sánchez, R. J., 1982, Geologic evolution of the Sierra Madre Oriental between Linares, Concepción del Oro, Saltillo and Monterrey, Mexico: Austin, Texas, University of Texas, Tesis doctoral, $217 \mathrm{p}$.

Padilla y Sánchez, R. J., 1986, Post Paleozoic tectonics of northeast Mexico and its role in the evolution of the Gulf of Mexico: Geofísica Internacional, 25, 157-206.

Salvador, A., 1991, Origin and development of the Gulf of Mexico basin, en Salvador, A., (ed.), The Gulf of Mexico basin: Boulder, Colorado, Geological Society of America, Geology of North America, J, 389-444.

Santamaría, O. D., Ortuño, A. F., Adatte, T., Ortíz, U. A., Riba, R. A., Franco, N.S., 1991, Evolución geodinámica de la Cuenca de Sabinas y sus implicaciones petroleras, estado de Coahuila: México, Instituto Mexicano del Petróleo, Reporte interno.

Suter, M., 1991, State of stress and active deformation in Mexico and western Central America, en Slemmons, D.B., Engdahl, E. R., Zoback, M. D., Blackwell, D. D. (eds.), Neotectonics of North America: Boulder, Colorado, Geological Society of America, 401-421.

Valdez-Moreno, G., 2001, Geoquímica y petrología de los campos volcánicos Las Esperanzas y Ocampo, Coahuila, México: México, Universidad Nacional Autónoma de México, Instituto de Geología, Tesis Maestría, 104 p.

Manuscrito recibido: Agosto 24, 2004

Manuscrito corregido recibido: Diciembre 18, 2004

Manuscrito aceptado: Enero 6, 2005 